\title{
SIMULATION STUDY ON THE INFLUENCE OF GREENING RATE OF URBAN RESIDENTIAL CLUSTERS ON THE DISTRIBUTION OF SUSPENDED PARTICULATE MATTERS
}

\author{
MA, $\mathrm{X}^{*}-\mathrm{ZHAO}, \mathrm{J}$. \\ School of Architecture, Chang'an University, Xi'an 710064, China \\ (e-mail:2232390994@qq.com) \\ *Corresponding author \\ e-mail:maxina861005@126.com \\ (Received 27 $7^{\text {th }}$ Sep 2018; accepted $16^{\text {th }}$ Jul 2019)
}

\begin{abstract}
Micro-climatic factors of landscape green space have provided dynamic conditions and thermal conditions for the distribution of suspended particulate matters. In this paper, the data of greening rate and micro-climatic factor of 88 residential areas were acquired, by means of field survey, spot test and CFD (Computation Fluid Dynamics) analog simulation. Through analysis of the previous relevant theoretical research and work, with the greening rate of residential clusters in Chinese Shanxi Province Xi'an as the research object, this study has reasonably set the value of the greening rate and built the physical models of the greening rate. In this study, the relationship among the various factors was obtained by analyzing the measured data. Meanwhile, CFD numerical models were verified, and the influence of the greening rate on wind speed, turbulence characteristics and concentration of suspended particulate matters were simulated. Finally, it concluded that the optimal cluster plan is $35 \%$ and $40 \%$ greening rate, while the cluster plan of $0 \%$ and $25 \%$ greening rate is inappropriate.
\end{abstract}

Keywords: green area ratio, residential groups, CFD simulation, suspended particulate matter

\section{Introduction}

Winston Churchill, British Prime Minister, once said that we shape our dwellings and afterward our dwellings shape. There is no doubt that modern urban construction will change the climate and living environment and directly affect the quality of life of residents (Periáñez, 2005). Urbanization has now become the main theme of the world's social and economic development. From a worldwide perspective, the world's urban population only accounted for $3 \%$ in 1800 . After the industrial revolution, urbanization accelerated development and up to 2000, the world's urban population accounted for $55 \%$, which is also the first time in human history that the urban population is larger than the rural population. In the face of the global urbanization development, the population changes of all countries show different pace. As shown in Figure 1, in the developed countries, due to the early start of urbanization and the high level of urbanization, the infrastructure of villages and towns is relatively perfect. With the increasing demand for urban environmental quality, the growth of urban population tends to be stable, and the phenomenon of population flowing back to villages and towns makes the cities of developed countries suburbanized; however, in the developing China, the urbanization starts late, the level is low and the development speed is very fast. Because of the abnormal development of the urban economy, the urban population grows rapidly. In order to meet the needs of the fast-growing population, the urban starts to expand construction blindly and unrestrictedly, which leads to the rapid decline of the environmental quality, serious traffic congestion and poor living conditions and other environmental and social problems. In China, the growth of urban population 
shows a sharp trend. As shown in Figure 2, in 1950, China's population was 545 million, of which only $12 \%$ was 654 million. In 2000, there were 453 million people in urban areas. It is estimated that by 2025,851 million people will live in cities (World population forecast by United Nations: Demographic Data of 2009, http://esa.un.org/upod/wup/dov_highights.htm).

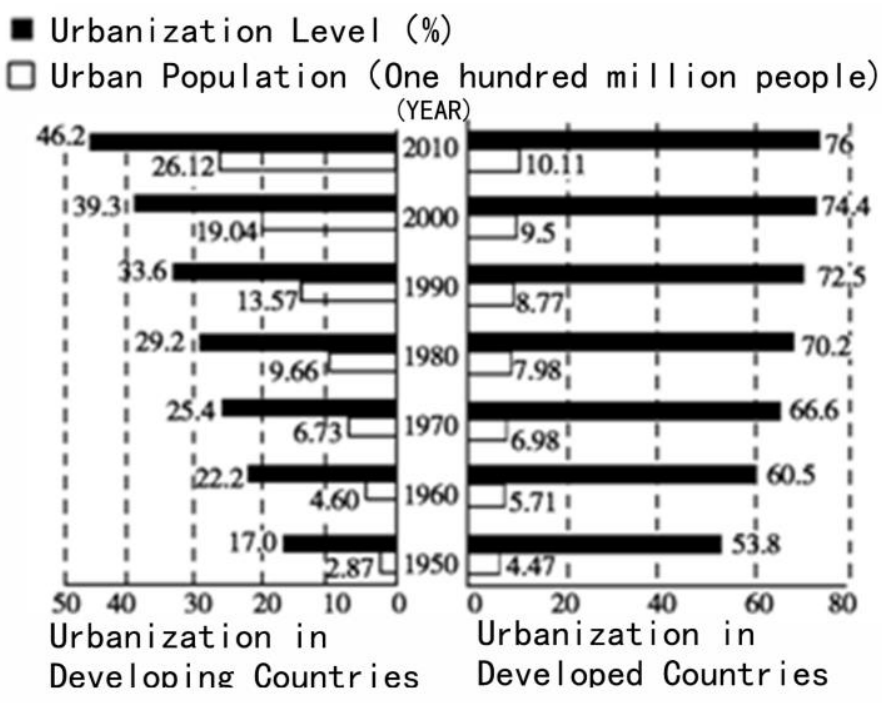

Figure 1. World urbanization process

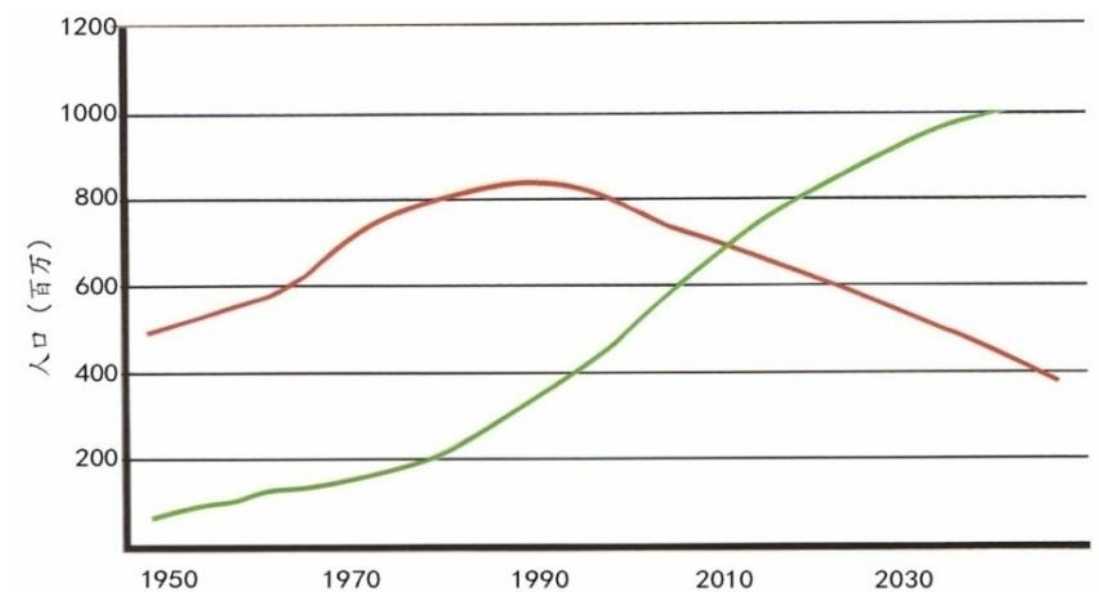

Figure 2. The increase of rural population (red) and urban population (green) in China

In the process of such rapid urbanization, not only the number of urban residents has increased, but also the urban land cover has been replaced by artificial paving materials from natural landforms. At the same time, the production and life of the city is maintained by the throughput of energy and raw materials (urban flow). In this process, it is inevitable to produce pollutant deposition in the form of energy and substance in the environment. These pollutants change the composition of urban atmospheric thermal structure and material form and affect urban climate and environment. Different forms and functions of urban areas form different local microclimates, which directly affect the quality of near-ground environment (Fig. 3). At present, the most concerned and 
discussed phenomenon of urban environmental pollution is haze, which has the greatest impact on human life and production. The air quality is related to the concentration distribution of suspended particulate matter, which has been paid close attention by scholars, managers and builders in various fields and even ordinary residents. There have been many pollution incidents about air pollution all over the world, which are due to the serious impact and harm of gaseous pollutants on local people in foggy weather or solid pollutants in bad weather conditions. In recent years, a wide range of haze in China has seriously affected the health and normal life of residents, whose fundamental reason is the atmospheric environmental pollution caused by suspended particulate matter. A large number of studies have also shown that the concentration of atmospheric suspended particulate matter, especially small particle size, has a significant impact on the health of human and animal respiratory system and shows a significant positive correlation. Particularly, small granule matters are very easy to adsorb organic pollutants, acid oxides, heavy metals, viruses and bacteria in the air, which are suspended in the atmosphere for a long time. It is harmful to human body and other animals through large-scale wind transmission (Ding, 2011; Peng, 2002).

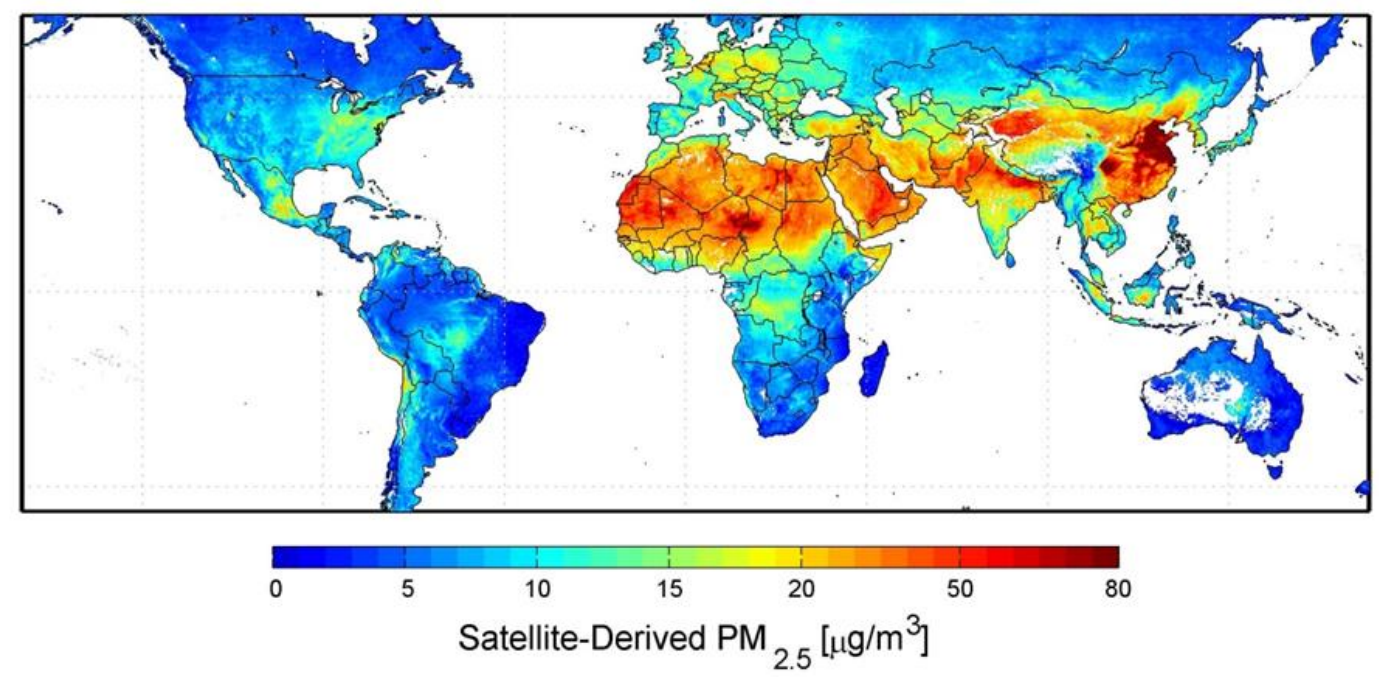

Figure 3. Global air quality map released by NASA in September 2010

Landscape garden is the most important place for urban activity and outdoor space in urban area, and the micro-climate changes in its spatial form affect the distribution of suspended particulate matters directly. Figure 4 has shown the interactional relationship between climate and artificial environment. Climate acts on the environment where people live, people create an urban environment, which is better for living and production. However, with urban development and construction, urban spatial form conducts feedback to the atmospheric environment, where heat of the smooth and impervious underlying surface of the city conducts convection directly on the city surface due to lack of moisture and vegetation. The T thermal energy then rises and is transmitted to the atmosphere. Meanwhile, the nearby air temperature changes rapidly, enabling the city to be covered under the dry and warm lid. The difference between microclimate and the background climate occurs in certain areas of the city. In addition, under the influence of microclimate, a variety of special climatic phenomena, such as heat island and haze appearing in some areas and they differ from natural climate. 


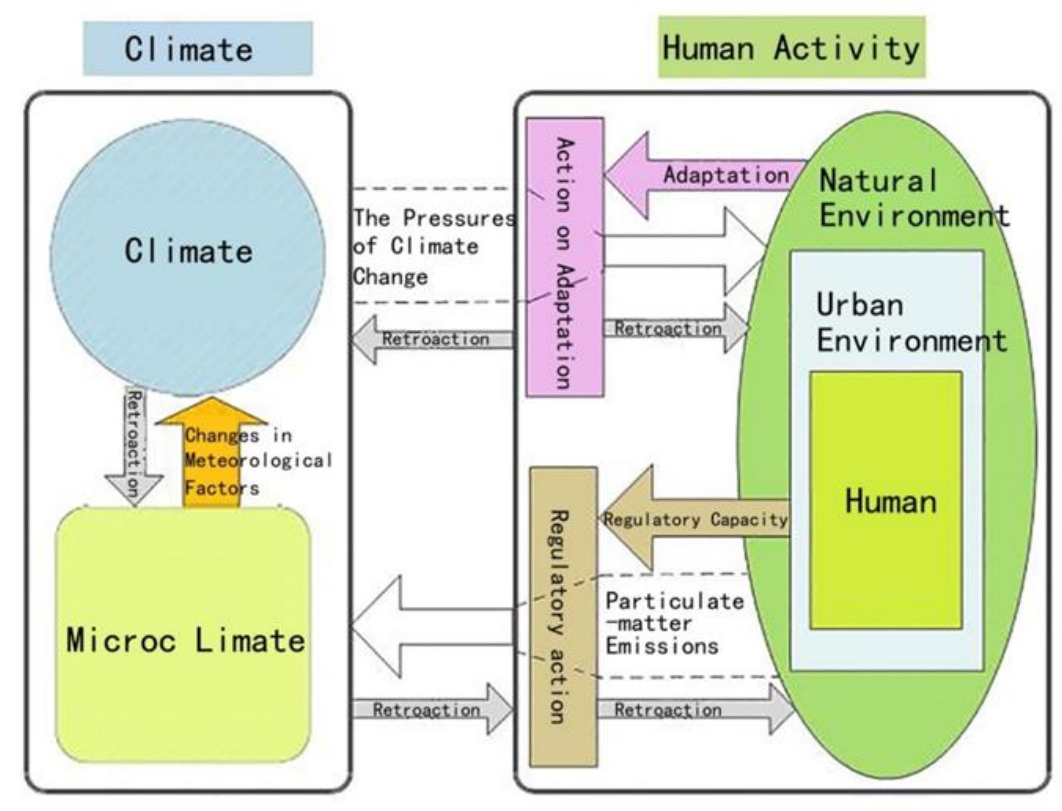

Figure 4. Interaction among microclimate, climate and artificial environment (Dai Tianxing, 2006)

According to aerodynamic equivalent diameter, air pollution particulate matters can be classified into TSP $(\leq 100 \mu \mathrm{m}), \mathrm{PM} 10 \leq 10 \mu \mathrm{m})$ and PM2.5 $(\leq 2.5 \mu \mathrm{m})$, etc., where the particulate matters with the grain size of less than $10^{\mu \mathrm{m}}$ are known as inhalable particulate matters. Since they closely relate to human health, they have raised extensive attention (Zhang, 2015). Figure 5 shows data comparison of major air pollutants in Xi'an from 2007 to 2017, indicating that the concentration of inhalable particulate matters is far higher than $\mathrm{SO}_{2}$ and $\mathrm{CO}_{2}$, and the pollution is especially obvious in winter. Therefore, the inhalable particulate matters have become the major air pollutants, which cannot be ignored.

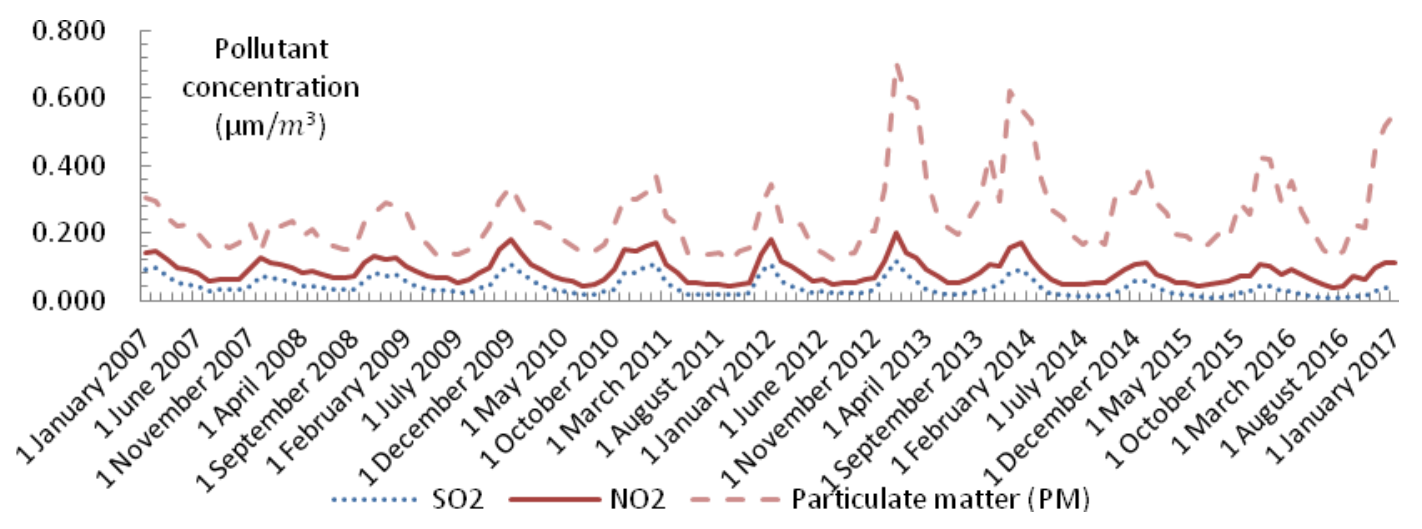

Figure 5. Comparison of monthly mean concentration of air pollutants from 2007 to 2017 made by Xi'an Meteorological Bureau

The concentration of ground pollutants is the major research object of this paper. This index mainly targets at the pollution of suspended particulate matters in people's 
daily life. This is because human activities are mainly outdoor, while the outdoor ground pollutants directly harm human body. This index can be obtained via either air pollution level or field test. This paper conducted comparison of the PM2.5 concentration of the rigid pavement and green space in the Dependent's Area of Chang'an University, Xiaozhai Commercial District, Xi'an. This study collected data at 11:00 a.m. On each day from January 30, 2015 to March 23, 2015, which was obtained by the Meteorological Bureau. Moreover, what have been published by Xi' an Municipal Environmental Protection Bureau indicate that the law of the two are almost the same. However, the measured values are obviously greater than the published meteorological data. According to the Technical Guidelines for Fugitive Emission Monitoring of Air Pollutants HJ/T55-2000 and Ground Meteorological Planning issued in 2004: the data of wind environment and pollutants are usually obtained through tests on the meteorological tower in suburb area, which is higher than $10 \mathrm{~m}$. While the values in this paper were acquired at the human respiration altitude of $1.5 \mathrm{~m}$ away from the ground, as the near-surface concentration values, for which Figure 6 shows the obvious difference between the two. Therefore, the practical research value of the measured values is greater (Fig. 7).

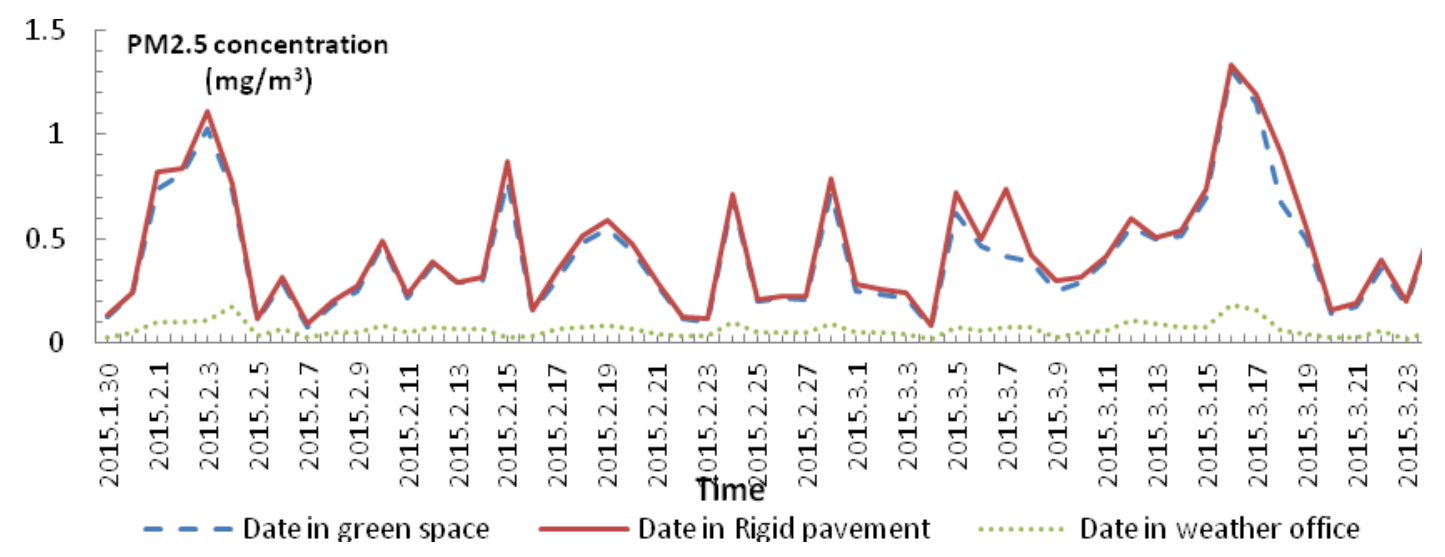

Figure 6. Comparison of the measured data and published meteorological data of PM2.5 from January to March 2015

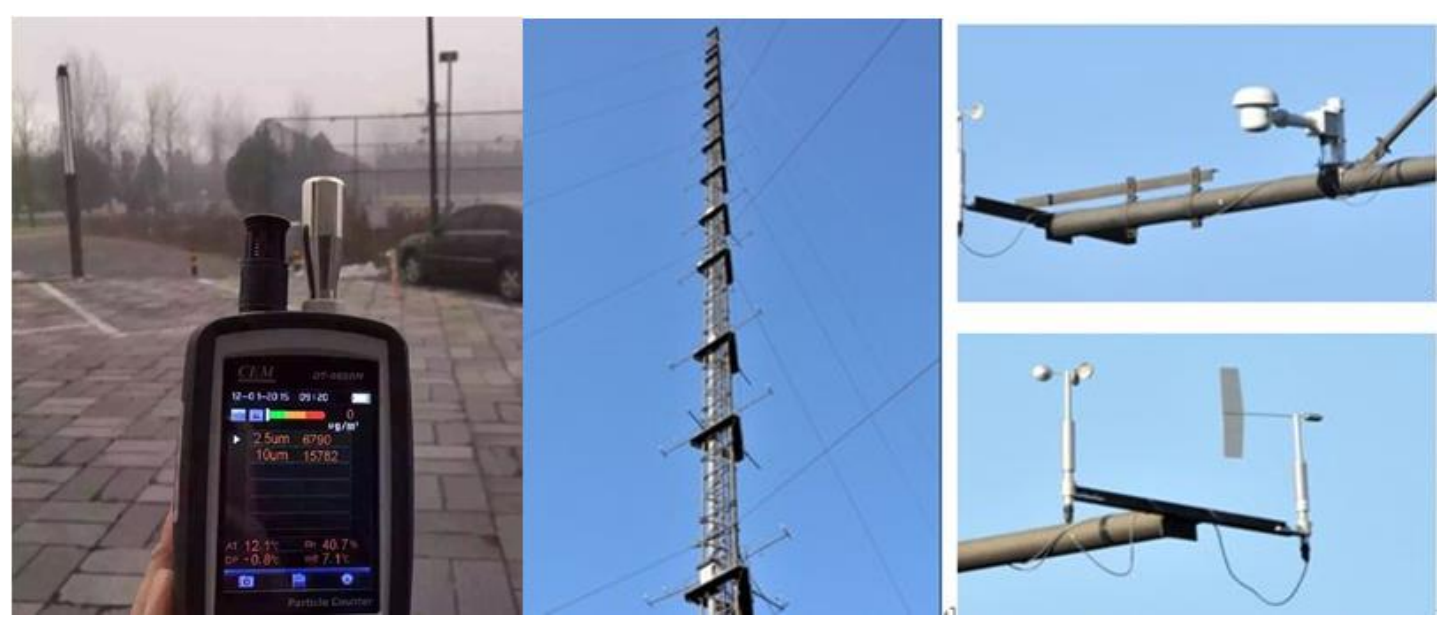

Figure 7. The near-surface test equipment $1.5 \mathrm{~m}$ away from the ground and meteorological observation iron tower 
In landscape garden, the dust settling effect of plants mainly results from the absorption and settling of particulate matters in the air by blocking the wind speed enabled by plant leaves. Buccolieri et al. (Nikolopoulou et al., 2001) found through wind tunnel test and CFD simulation that arbors on urban streets can improve wind environment and settle pollutants. However, due to different thickness of leaves and density of branches and leaves of various vegetation in greenbelts, dust retention differs per plant species It was found by Meir et al. (2000) through research that dust retention of trees and shrubs is far greater than that of lawns. In park green space and roadside green space, dust retention of shrubs per unit leaf area is higher than that of arbors. Many researches have proved that arbor leaves mainly retain large-grained flying dust, while shrubs set dust materially since they can better prevent pollution caused by the near-ground particulate matters (Zhou, 2001). In some researches, the relationship between the form of greenbelts and concentration of particulate matters is discussed from the perspective of the spatial arrangement of greenbelts. Feng et al. (2014) and Feng and Chu (2017) investigated and compared the urban green space, and concluded that pollutant dispersion presents positive relationship with green land area, and different green land area of residential areas, especially different trees and shrubs majorly contribute to dust retention of residential areas. There have been quite a few domestic and foreign scholars (Zhu et al., 2002; Che and Song, 2002; Su et al., 2002; Chai et al., 2002; Fanger and Toftum, 2002) with dedicated researches on the elimination rate of greenbelts of different structures towards particulate matters, with a consistent finding: under the same community structure, the effect of PM2.5 reduction by greenbelts is better than that of PM10 reduction.

The above research shows that suspended particulate matters are closely related to greening rate and characteristics of plant leaves due to the effect of microclimate. Moreover, dust retention of shrubs per unit leaf area is the best among other plant species. Therefore, by analyzing microclimate characteristics in this paper, shrubs were selected as the vegetation for research, and the design threshold of greening rate in residential clusters was preset reasonably, to study the distribution of PM2.5 of inhalable suspended particulate matters.

\section{Materials and methods}

\section{Establishment of physical models}

In this paper, residential quarters with 1,000-3,000 residents or 300-1,000 households in Xi' an were screened according to the study on the characteristics of urban residential clusters. Based on the scale characteristics of residential clusters, visit and investigation were carried out on 88 selected residential clusters in Xi'an, and the greening rate of the various community clusters were sorted out and analyzed. Figure 8 indicates that the greening rate of the residential living clusters in Xi'an is mainly around the ranges of $30 \%, 35 \%$ and $40 \%$.

It is expressly stipulated in the Code of Urban Residential Areas Planning and Design GB50180-93 (2002) that for the construction of new residential areas, the greening rate shall not be lower than $30 \%$, and the greening rate shall not be lower than $25 \%$ for the reconstruction of old residential areas. It is stated by Article 14 in Regulations of Xi'an Municipality on the Administration of Urban Greening executed on June 1, 2014 that the greening rate of new residential areas shall not be lower than $35 \%$, while the greening rate of residential areas under old city reconstruction shall be 
$5 \%$ lower in comparison, namely $30 \%$. When building the models, the assumed greening rate of $25 \%, 30 \%, 35 \%, 40 \%$ and $0 \%$ shall be adopted combining the relevant standards and the practical cognitions of $\mathrm{Xi}$ 'an to enhance the comparability of simulated results, as shown in Figure 9.

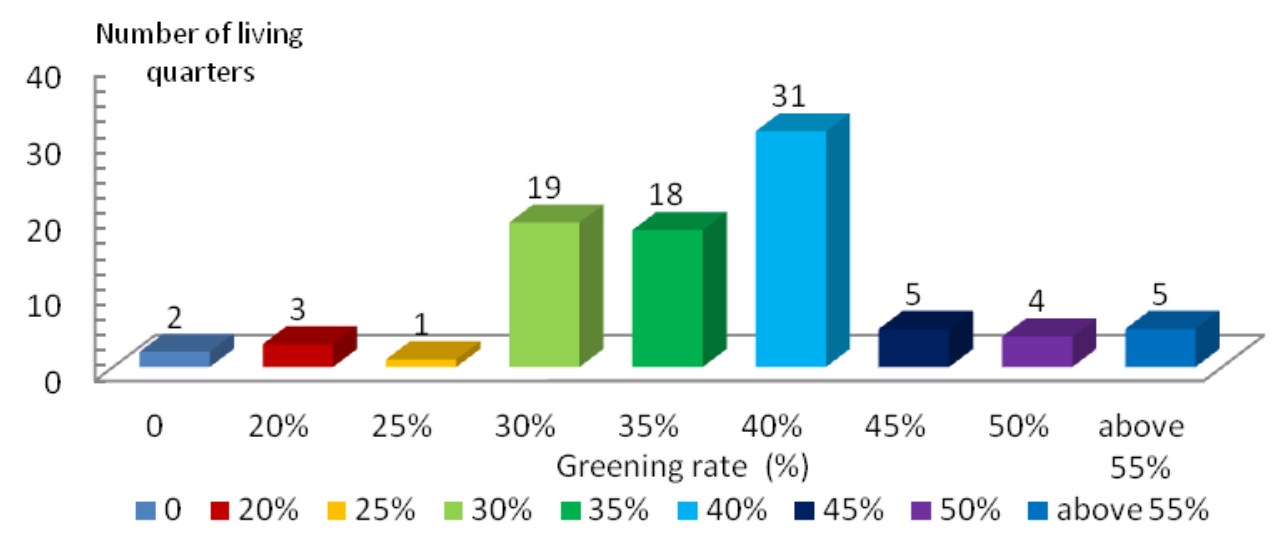

Figure 8. Statistics of the greening rate in Xi'an through field survey

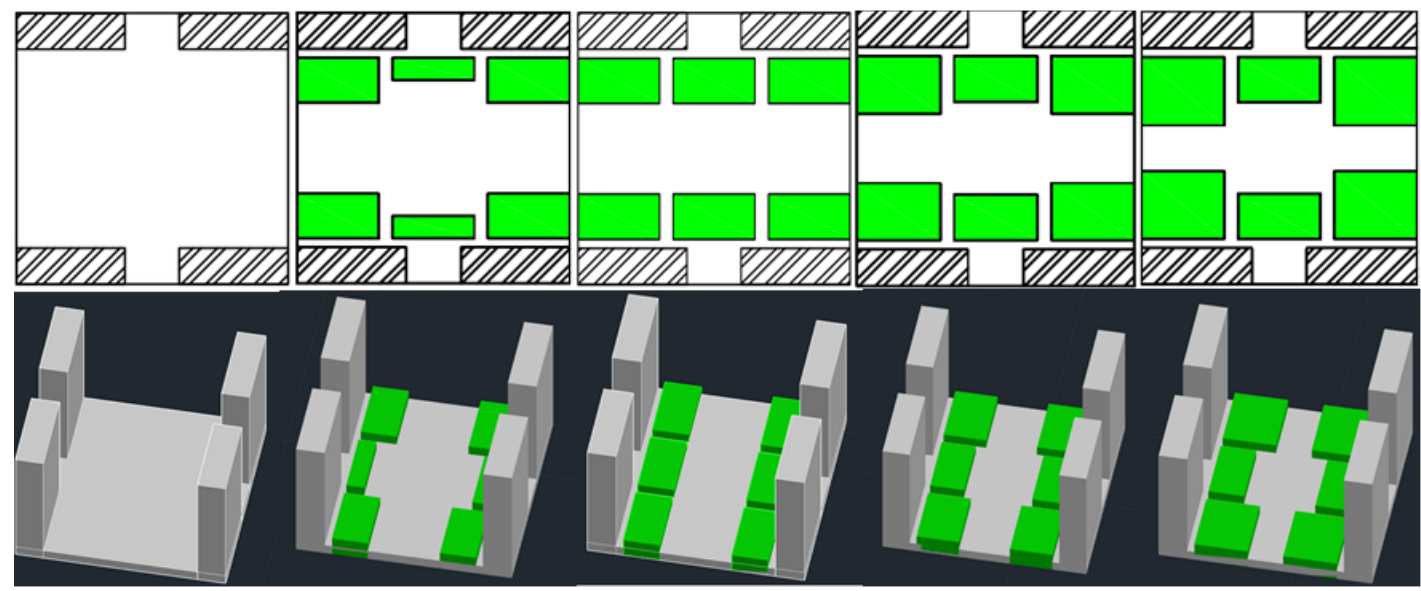

Greening rate: $0 \%$ Greening rate: $25 \%$ Greening rate: $30 \%$ Greening rate: $35 \%$ Greening rate: $40 \%$

Figure 9. Plane and aerial view of different greening rate models

\section{CFD numerical calculation model}

According to the residential cluster space studied in this paper, Autodesk Simulation CFD was selected for the outdoor microclimate research thereof, given the fact that Autodesk Simulation CFD has high intelligence, strong automatic mesh generation technology, powerful analysis functions, high degree of humanization of post processing, and can conduct comparative analysis, etc. Its main functions are simulated analysis of fluid flow, heat transfer and movement $(\mathrm{Hu}, 2002)$. In this paper, the distribution of suspended particulate matters and flow field in the residential cluster space of different building height were simulated elaborately, with the powerful automatic mesh partitioning technology of the most common and mature turbulence model as well as Autodesk Simulation CFD, through the discretization and solution of differential equation. 


\section{Standard $\mathrm{k}-\varepsilon$ turbulence model}

In the study on urban outdoor environment, the most frequently used model is the standard $\mathbf{k}-\mathbf{\varepsilon}$ turbulence model. Such model focus on the turbulent dissipation rate and turbulence function. Suppose that both the inside and outside of the flow field are turbulence, the viscosity between molecules are ignored, and the standard model $\mathbf{k}-\boldsymbol{\varepsilon}$ is built and functioning effectively ( $\mathrm{Hu}, 2002$; MOHURD, 2010). In this paper, this model was taken as the research model. As a semi-rational formula, its equation is as follows:

$$
\begin{gathered}
\frac{\partial \mathrm{k}}{\partial \mathrm{t}}+\frac{\partial}{\partial \mathrm{t}_{\mathrm{j}}}\left(\mathrm{u}_{\mathrm{j}} \mathrm{k}\right)=\frac{\partial}{\partial \mathrm{t}_{\mathrm{j}}}\left[\left(\mathrm{v}_{0}+\frac{\mathrm{v}_{\mathrm{t}}}{\sigma_{\mathrm{k}}}\right) \frac{\partial \mathrm{k}}{\partial \mathrm{x}_{\mathrm{j}}}\right]+\mathrm{G}-\varepsilon \\
\frac{\partial \varepsilon}{\partial \mathrm{t}}+\frac{\partial}{\partial \mathrm{t}_{\mathrm{j}}}\left(\mathrm{u}_{\mathrm{j}} \varepsilon\right)=\frac{\partial}{\partial \mathrm{t}_{\mathrm{j}}}\left[\left(\mathrm{v}_{0}+\frac{\mathrm{v}_{\mathrm{t}}}{\sigma_{\varepsilon}}\right) \frac{\partial \varepsilon}{\partial \mathrm{x}_{\mathrm{j}}}\right]+\frac{\mathrm{C}_{1} \varepsilon}{\mathrm{k}} \mathrm{G}-\mathrm{C}_{2} \frac{\varepsilon^{2}}{\mathrm{k}}
\end{gathered}
$$

where $\mathrm{k}$ - turbulence energy; $\varepsilon$ - turbulent energy dissipation rate; $\sigma_{\mathrm{k}}, \sigma_{\varepsilon}, \mathrm{C}_{1}$ and $\mathrm{C}_{2}$ empirical constant; $\mathrm{G}$ - generation of turbulent energy, expressed as:

$$
\mathrm{G}=\mathrm{v}_{\mathrm{t}}\left(\frac{\partial \mathrm{u}_{\mathrm{i}}}{\partial \mathrm{x}_{\mathrm{j}}}+\frac{\partial \mathrm{u}_{\mathrm{j}}}{\partial \mathrm{x}_{\mathrm{t}}}\right) \frac{\partial \mathrm{u}_{\mathrm{i}}}{\partial \mathrm{x}_{\mathrm{j}}}
$$

\section{Discretization and solution of differential equation}

The study in this paper has adopted the Finite Volume Method (FVM), with which, the entire computation field was first divided into several control volumes for mesh processing. Then, the differential equation was set for discretization processing with related schemes. Finally, the boundary conditions and initial conditions were supplemented, unknown parameters of all points of the space were solved, and a satisfactory result was finally obtained through repeated iteration. FVM has high computational efficiency, as it can indicate accurately integral conservation when the meshes are not very precise (Ma et al., 2017).

\section{Mesh size and division}

In the process of numerical simulation, mesh division of the models played an important part affecting the calculation of simulation values. To reduce the impact of the mesh boundary on its central area, and reduce the calculation of excessive loss due to oversize mesh, fineness of the mesh partition unit for the models of the residential areas was adjusted to around 0.3. In large blocks, Uniform Mesh was adopted, while Non-uniform Mesh was brought in small blocks, providing possibilities for depicting more precise flow fields.

\section{Initial value of PM2.5 concentration field}

The annual mean PM2.5 concentration of Xi'an in 2014 was higher than the secondary national ambient air quality standard by 1.17 times (Ma et al., 2017). The 24- 
h mean concentration of the $95^{\text {th }}$ percentile was 194 , higher than the secondary standard of the daily mean value of national ambient air quality standards by 1.59 times (Pape et al., 2014). The daily mean value of the monitoring points was $11-506 \mathrm{mg} / \mathrm{m}^{3}$, and the maximum surpassing times was 5.75 times higher (Code for planning and design of urban residential areas GB50180-2002, 2002). Since urban buildings have high density, the emission sources of single suspended particulate pollutants lead to low emissions. However, if they are in great quantity, emission sources can be considered as the spread mode of non-point source pollution (Feng and Wang, 2004). In this paper, only the background concentration of PM2.5 is considered, instead of the automobile exhaust or the influence of other complex surroundings. In the United States and Western Europe, the background concentration is about $3-5 \mu \mathrm{g} / \mathrm{m}^{3}$, and $5 \mu \mathrm{g} / \mathrm{m}^{3}$ (Sun et al., 2010; Peng Jiang, 2002; Salamanca et al., 2009) in Australia. There is still no public data available for China. According to the new Ambient Air Quality Standard published by Chinese government in March 2012, the value of $150 \mu \mathrm{g} / \mathrm{m}^{3}$ executed previously is still reserved as the daily mean concentration limit of PM10, the daily mean concentration of PM2.5$75 \mu \mathrm{g} / \mathrm{m}^{3}$ was set according to the proportion of PM2.5 to PM10-50\% (Horemans, 2007; Zhao and Liu, 2001).

\section{Experimental test}

\section{Summer experiment}

The experiment was conducted from January 16 to 17, 2015. In this group of experiments, 88 residential areas of Xi'an were selected with two measurement points for each residential area. The central square, open place and the space between two buildings were respectively selected as measurement points. For each measurement point, there were 1056 data. The theoretical analysis has showed that the air humidity of the greenbelts increases through plant transpiration, and wind environment of some areas could be improved through photosynthesis. Therefore, concentration of PM2.5 would decrease along with the increase of greening rate. The data was separated for summarization. The single factor greening rate was taken as the major cause for comparison with the concentration of PM2.5, and a trend chart was drawn accordingly. The analysis of the design factors and the data of PM2.5 concentration of the 88 residential areas has showed that the greening rate is negatively related to PM2.5 concentration (Figs. 10 and 11).

\section{Winter experiment}

\section{Selection of comparison group of green space rate}

The comparison group compared the influence of green space rate on PM2.5 diffusion distribution under the same heat island and volume rate. As shown in Table 1, the locations are Jinduicheng Garden District and Shengshi Chang'an, which have similar volume ratios of 2.8 and 2.55 respectively and are located in Chang'an District in the northern suburbs of Xi'an. Chang' an District surrounds Xi' an City from the south and west and Qinling Mountains in the south. The intensity of heat island is weak and the concentration of PM2.5 is at a low level. The difference of green rate between the two districts is obvious of which the green space rate of Jinduicheng Garden District is only $18 \%$, and that of Shengshi Chang'an is $65 \%$. The location and detailed test points of the two districts are shown in Figures 12 and 13 and Table 2. 


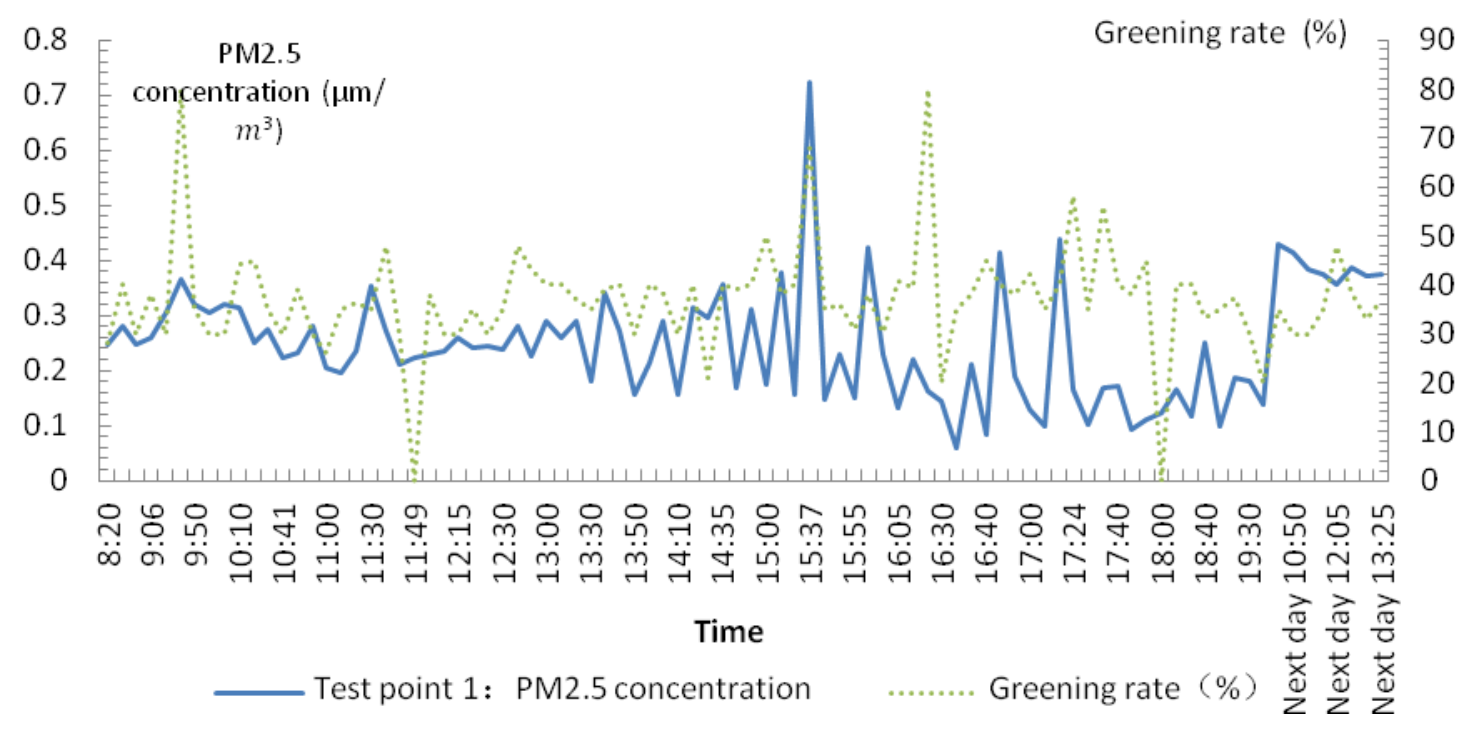

Figure 10. Comparison of the changes between open place greening rate and PM2.5 concentration

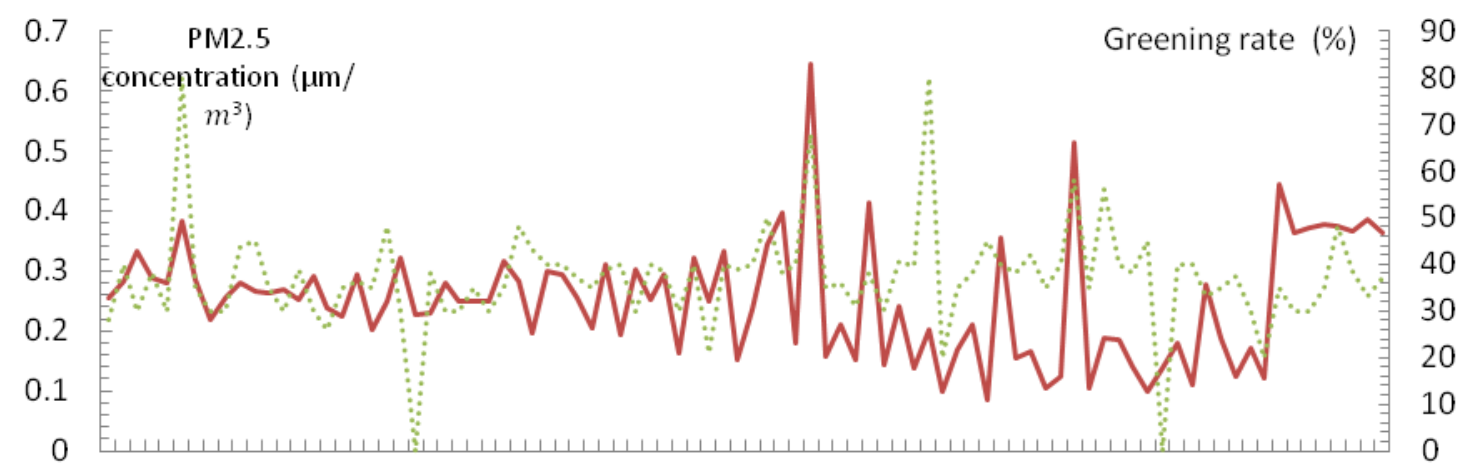

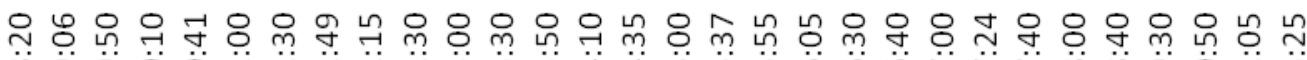

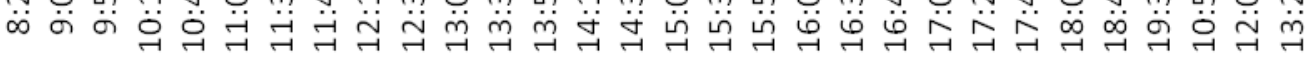

\section{Time}

Test point 2: PM2.5 concentration

Figure 11. Comparison of the changes between the greening rate of the space between two buildings and PM2.5 concentration

Table 1. Comparison survey of grouping factors

\begin{tabular}{c|c|c|c}
\hline Name & Location & Volume rate & Green space rate \\
\hline Jinduicheng Garden District & Chang'an & 2.8 & $18 \%$ \\
Shengshi Chang'an & Chang'an & 2.55 & $65 \%$ \\
\hline
\end{tabular}


Ma - Zhao: Simulation study on the influence of greening rate of urban residential clusters on the distribution of suspended particulate matters

-10345 -

Table 2. Maps of green space comparison groups

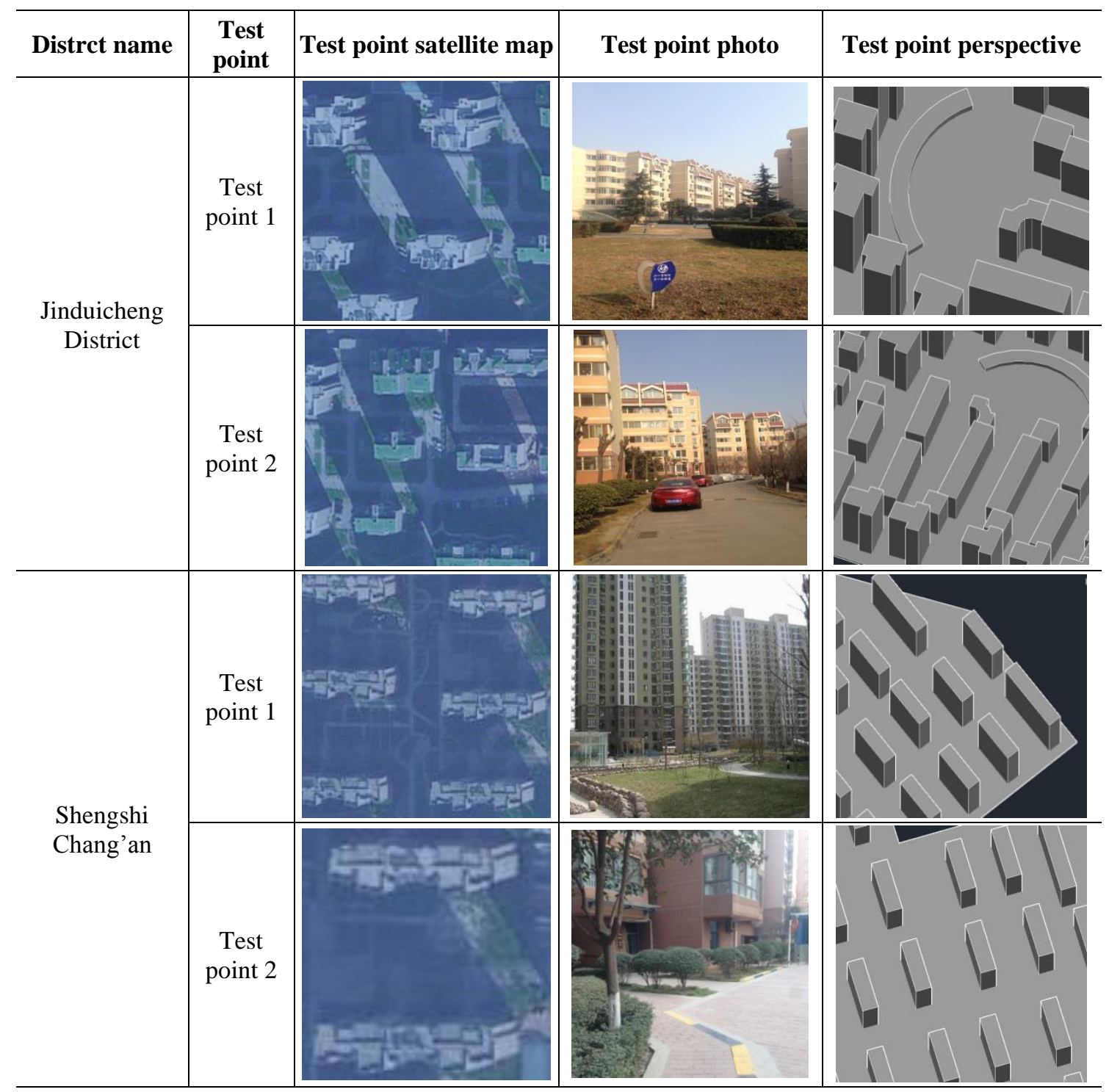

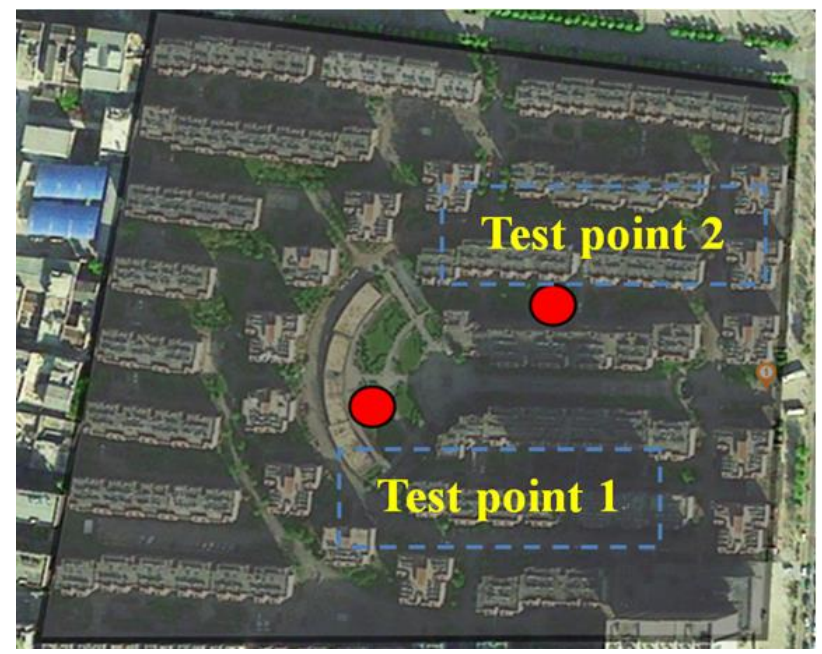

Figure 12. Distribution of test points in Jinduicheng District 


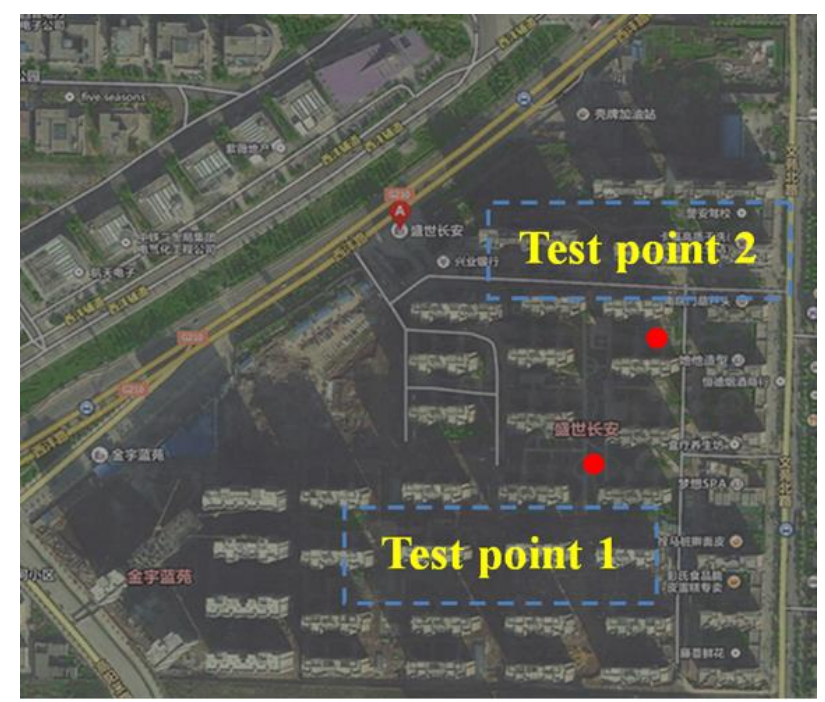

Figure 13. Distribution of test points of Shengshi Chang'an

\section{Test of the influence of green space rate on PM2.5 concentration}

During the experiment, every test point in each district is tested every hour. The test time is from 10:00 on January 15, 2015 to 10:00 on January 16, 2015. Detailed PM2.5 concentration analysis of the two districts is as follows:

It can be seen from Figures 14 and 15 that the concentration of PM2.5 in Shengshi Chang'an is basically lower than that in Jinduicheng District, but during the period from 8:00 to 17:00 in the daytime, the construction site near Shengshi Chang'an has affected the high concentration of particulate matter in the district. The two residential areas are located in Chang'an District, where the intensity of heat island is weak and the volume ratio is basically the same. It can be seen that the difference of PM2.5 concentration between the two residential areas is caused by the difference of green space rate. Plants can alleviate PM2.5 pollution due to their retention on particulate matter. From the experimental data, it can be seen that green space can reduce PM2.5 concentration to a certain extent. As shown in Figures 16 and 17, as a whole, because the test point 1 is located in the open central square and the test point 2 is located in the hard ground between the two buildings where the ventilation is not smooth. Because the greening around the test point 1 is higher than that around the test point 2 which causes higher PM2.5 concentration of the test point 2. The data at 5:00 in Shengshi Chang'an are obviously higher, which may be caused by the passing cars.

To define the microclimate factors affecting PM2.5 concentration, this paper has introduced linear-regression analysis, to study the relationship among temperature, humidity, wind speed and PM2.5, by following 3 processes. Firstly, choose analyze $\rightarrow$ regression $\rightarrow$ linear, and activate the dialog boxes popping up in sequence. To follow that, there shall be further analysis. Finally, review the output; make the regression equation and inspection. The final analysis results are shown by Table 3, where, 3.126 is the constant term, while the coefficient of temperature, humidity, wind speed and PM2.5 concentration are respectively $-2.198,0.153,0.045$ and 0.190 .

Since residuals are always assumed to obey normal distribution in the models, Table 3 demonstrates whether the actual residuals after regression fit this assumption. Besides, it shows that the degree of influence imposed by various influencing factors on 
PM2.5 concentration from high to low respectively: wind speed $(\mathrm{m} / \mathrm{s})>$ temperature $\left({ }^{\circ} \mathrm{C}\right)>$ humidity $(\% \mathrm{RH})$, where wind speed exerts the greatest influence on PM2.5 concentration, while humidity exerts the lowest influence. Since it is difficult to subside PM2.5, gas pollution can be deemed as in the atmosphere, while wind speed is just a direct performance indicator of gas flow. Upon actual measurement, the most relevant micro-climatic factor of the distribution of PM2.5 concentration shall be wind environmental impact. Due to the difficult of PM2.5 reduction, increase of humidity has no significant effect on its settlement.

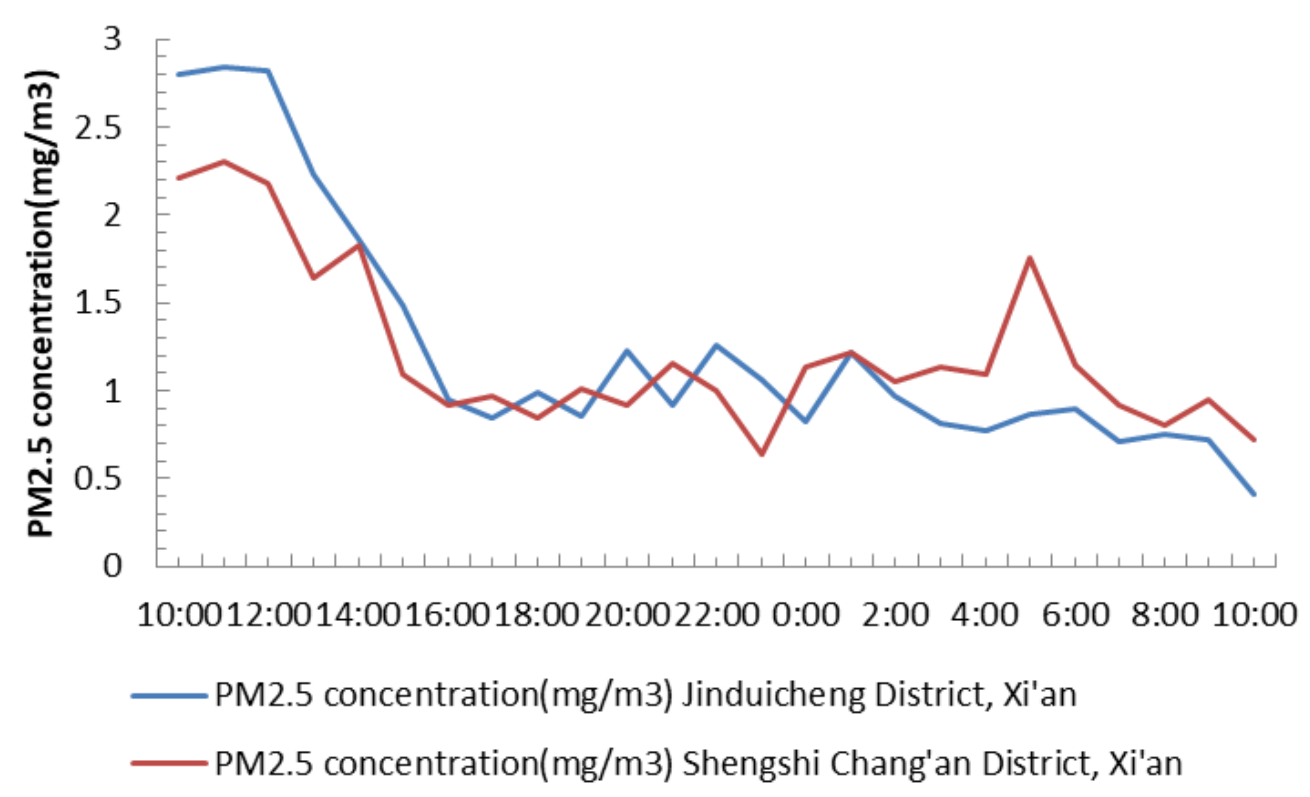

Figure 14. Comparison of PM2.5 concentration data at test point 1

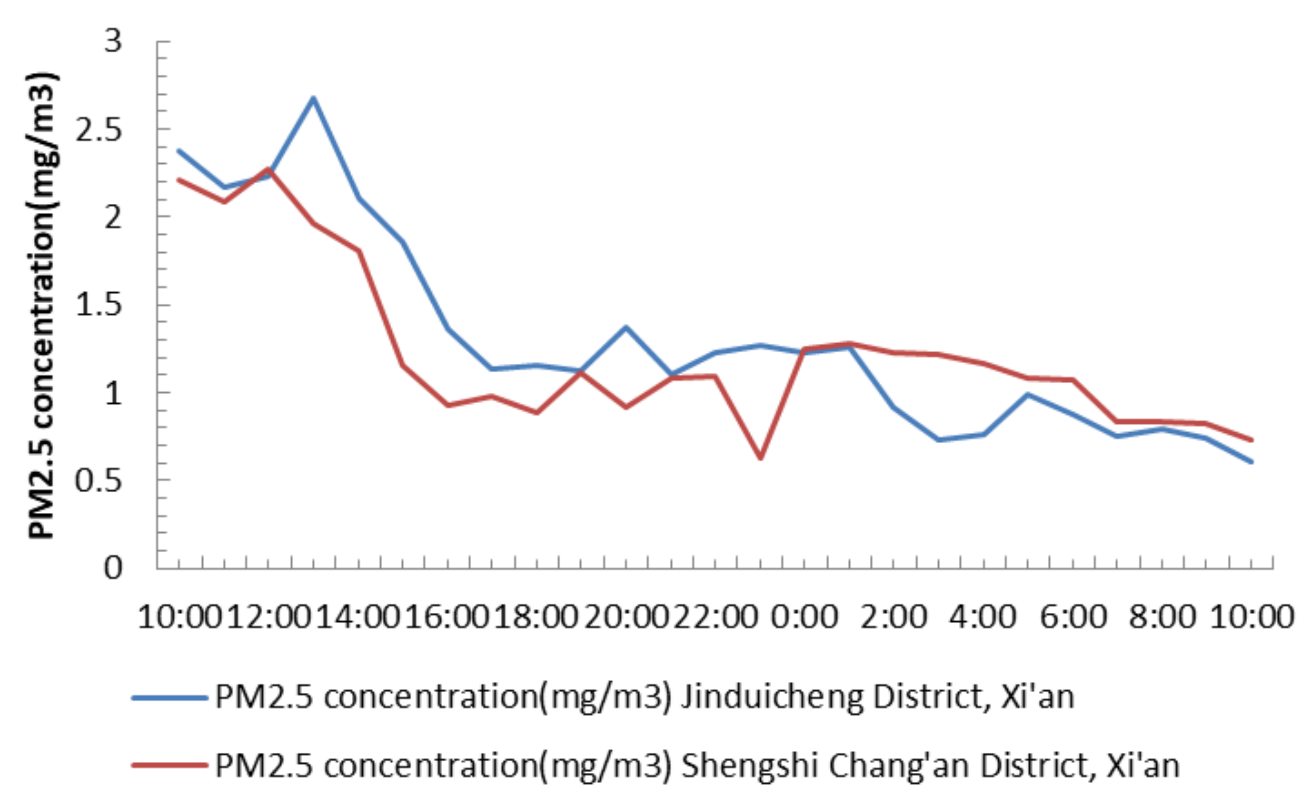

Figure 15. Comparison of PM2.5 concentration data at test point 2 


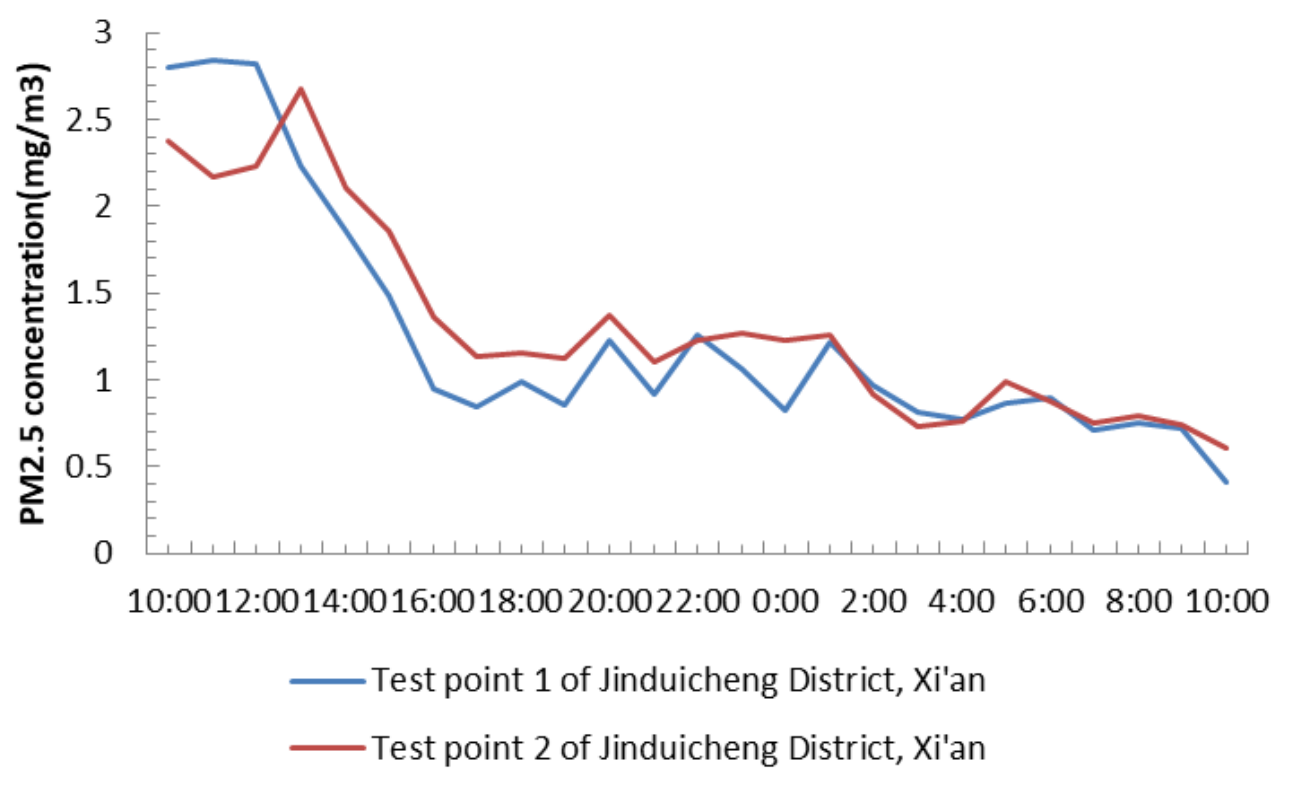

Figure 16. Comparison of PM2.5 concentration between test point 1 and test point 2 in Jinduicheng District

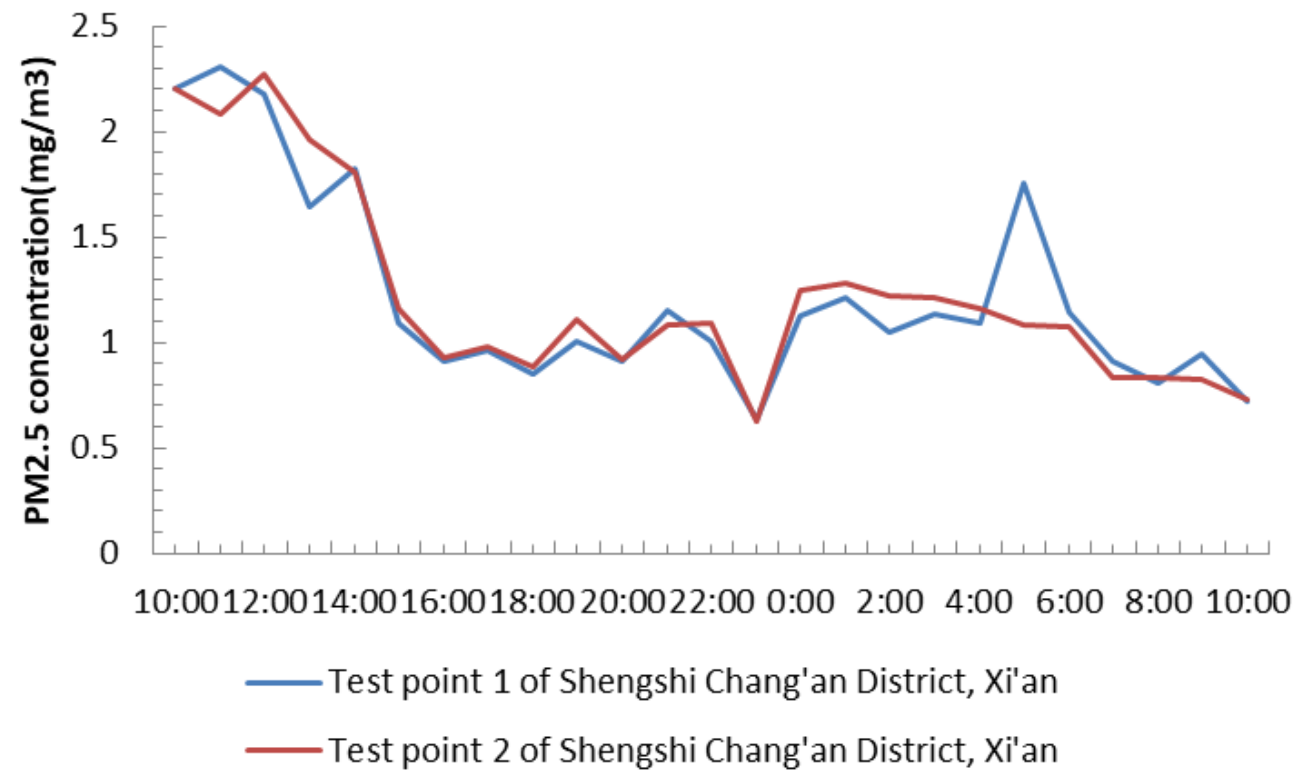

Figure 17. Comparison of PM2.5 concentration between Shengshi Chang'an test point 1 and test point 2

\section{Results}

Study in this paper conducted thermal pollution coupling calculation simulation of the greening rate of residential clusters in Xi'an, by building the physical model and CFD numerical calculation model. Furthermore, this paper has analyzed the effect of micro-climatic factors on improving the concentration distribution of suspended particulate matters through the influence of greening rate. After measurement 
verification, micro-climatic factors of wind environment are found mostly related to PM2.5 concentration (Li et al., 2017; Tian et al., 2017; Liu et al., 2017). Therefore, during the simulation, comparative analysis was only made on wind speed, turbulence characteristics, PM2.5 concentration and the greening rate.

Table 3. Coefficient of regression

\begin{tabular}{|c|c|c|c|c|c|}
\hline \multicolumn{6}{|c|}{ Coefficient $^{\mathrm{a}}$} \\
\hline \multirow{2}{*}{ Model } & \multicolumn{2}{|c|}{ Unstandardized coefficient } & $\begin{array}{c}\text { Standardized } \\
\text { coefficient }\end{array}$ & \multirow{2}{*}{$\mathbf{t}$} & \multirow{2}{*}{ Sig. } \\
\hline & B & Standard error & Trial version & & \\
\hline (Constant) & -2.198 & .139 & & -15.809 & .000 \\
\hline Temperature & .153 & .010 & .546 & 15.135 & .000 \\
\hline Humidity & .045 & .002 & .804 & 22.275 & .000 \\
\hline Wind speed & .190 & .058 & .112 & 3.288 & .001 \\
\hline
\end{tabular}

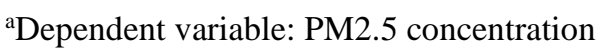

\section{Wind speed}

Figure 18 shows the planar wind speed distribution of different green land rates at an altitude of $1.5 \mathrm{~m}$, under the condition of perpendicular to the northeast wind. Figure 19 shows the comparison on the wind data of the gap between two green land parcels at an altitude of $1.5 \mathrm{~m}$ from north to south, at the fluid outlet on the west of the residential clusters. The comparison shows that wind speed in urban residential cluster space is negatively related to the greening rate. However, as the greening rate grows, its impact on wind speed weakens gradually. This is mainly because when the green land area is too large, airflow generated through transpiration of the plants can adjust the surrounding breeze or wind environment, and wind speed will not slow down linearly (Zamora Figueroa et al., 2017; Kmita et al., 2018). When the green land area is large enough, improvement made by the plants on the wind environment of the internal cluster space would be enhanced, and wind speed increases.
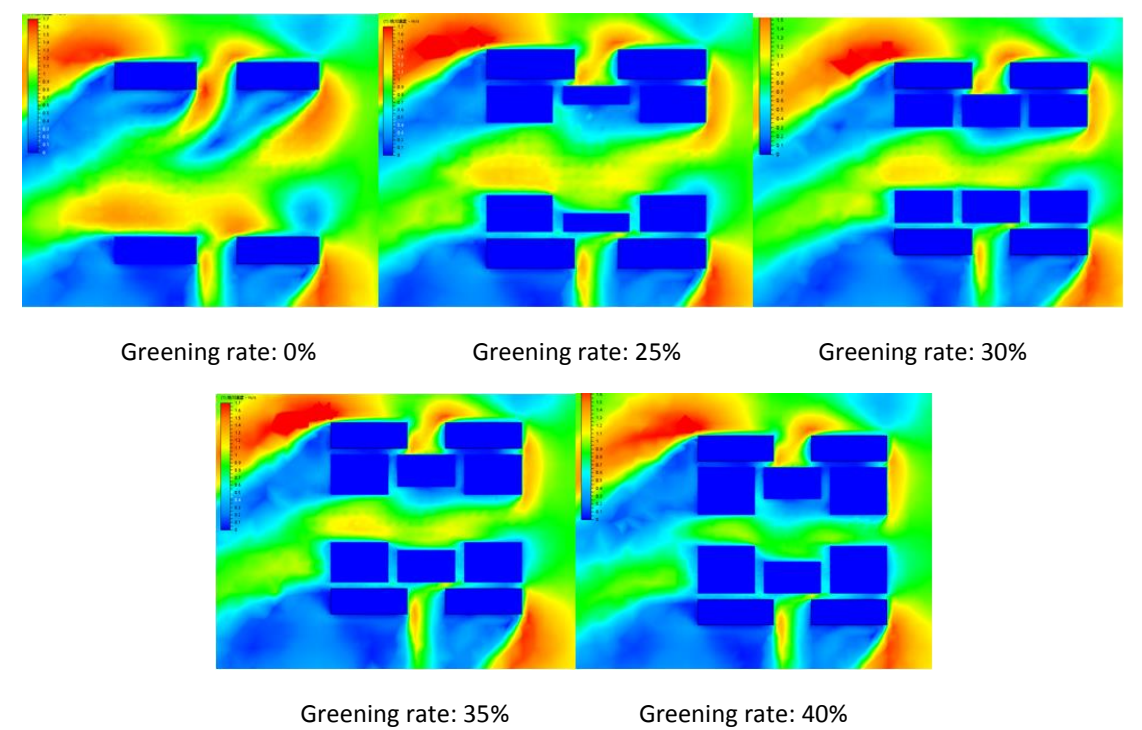

Figure 18. Planar fluid spread of clusters with different greening rates at an altitude of $1.5 \mathrm{~m}$ 


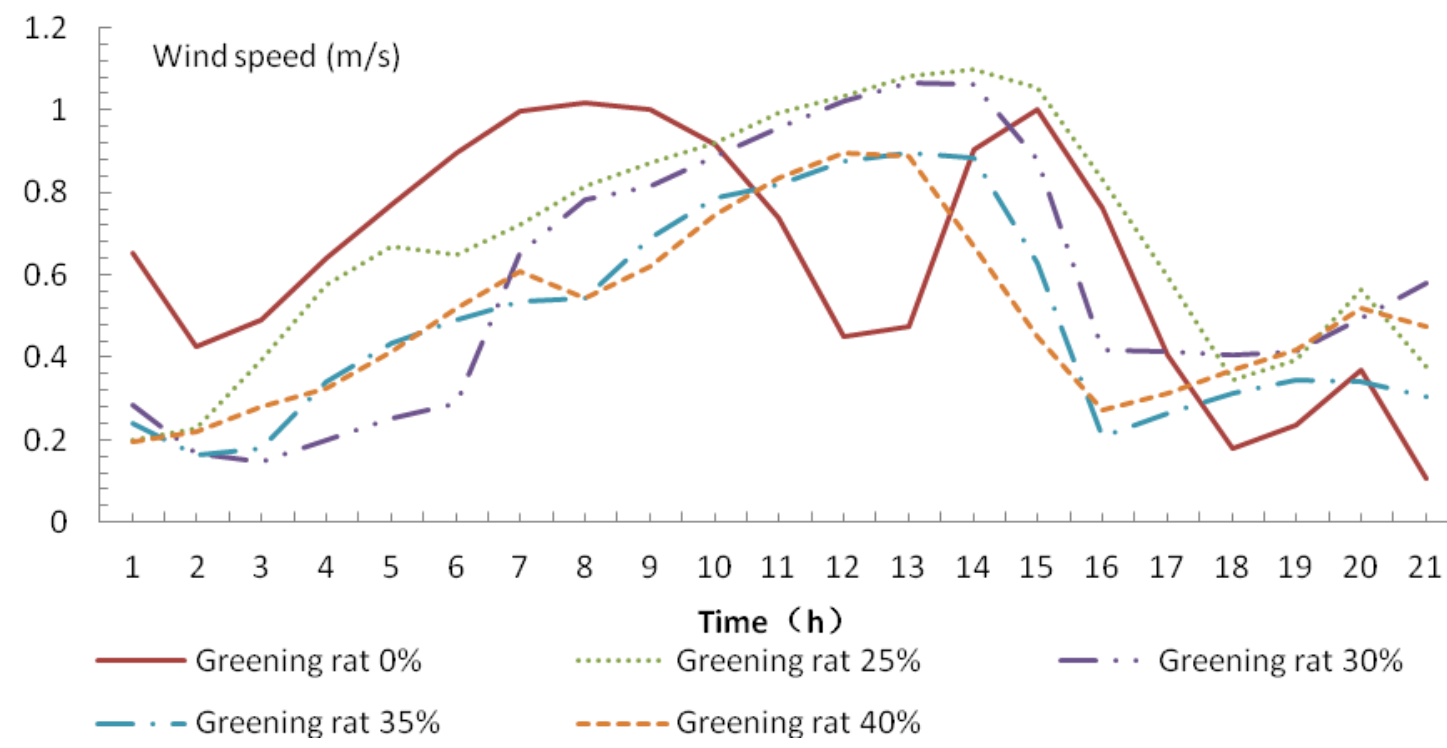

Figure 19. Distribution of wind speed on the west-side air outlet in the cluster space with different greening rates at an altitude of $1.5 \mathrm{~m}$

\section{Turbulence characteristics}

Figure 20 shows a section view of each cluster on the west-side air outlet, indicating the influence of cluster space with different greening rate of fluid. When under the condition that the buildings are unchanged, it is clear that the degree of changes made by different green land area towards internal fluid of the space vary, and it is especially significant on the surface of the buildings.

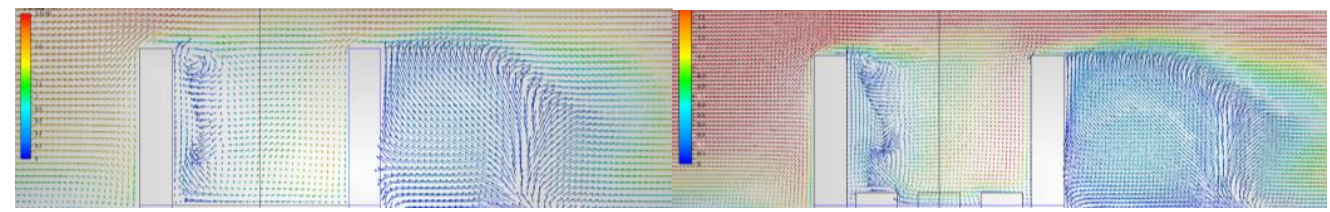

Greening rate: $0 \% \quad$ Greening rate: $25 \%$

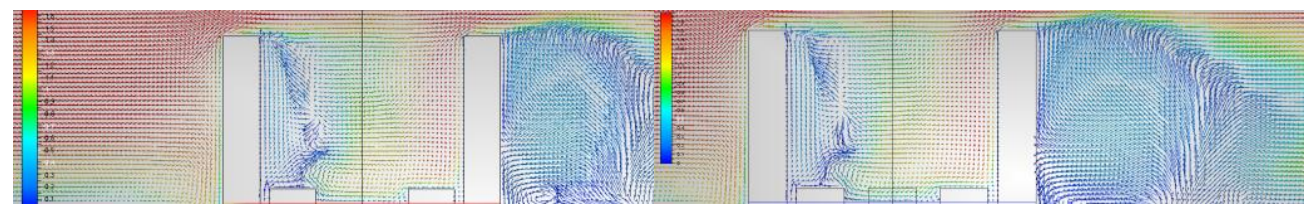

Greening rate: $30 \% \quad$ Greening rate: $35 \%$

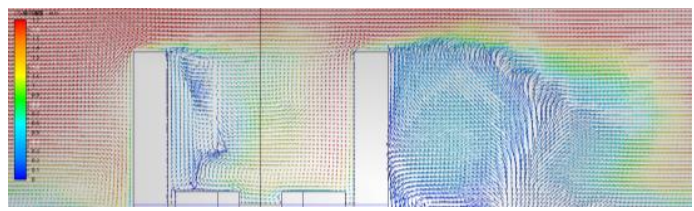

Greening rate: $40 \%$

Figure 20. Section view of wind velocity vector on the west-side outlet of fluid for clusters with different greening rates 


\section{Spread of pollutants in cluster space}

Figures 21 and 22 show the planar fluid spread distribution of different greening rates at an altitude of $1.5 \mathrm{~m}$ and the concentration distribution of fine particulate matters. As demonstrated, the concentration data of particulate matters from north to south in the gap between two west-side green land parcels of planar clusters at an altitude of $1.5 \mathrm{~m}$ was selected for comparison that is shown in Figure 22.

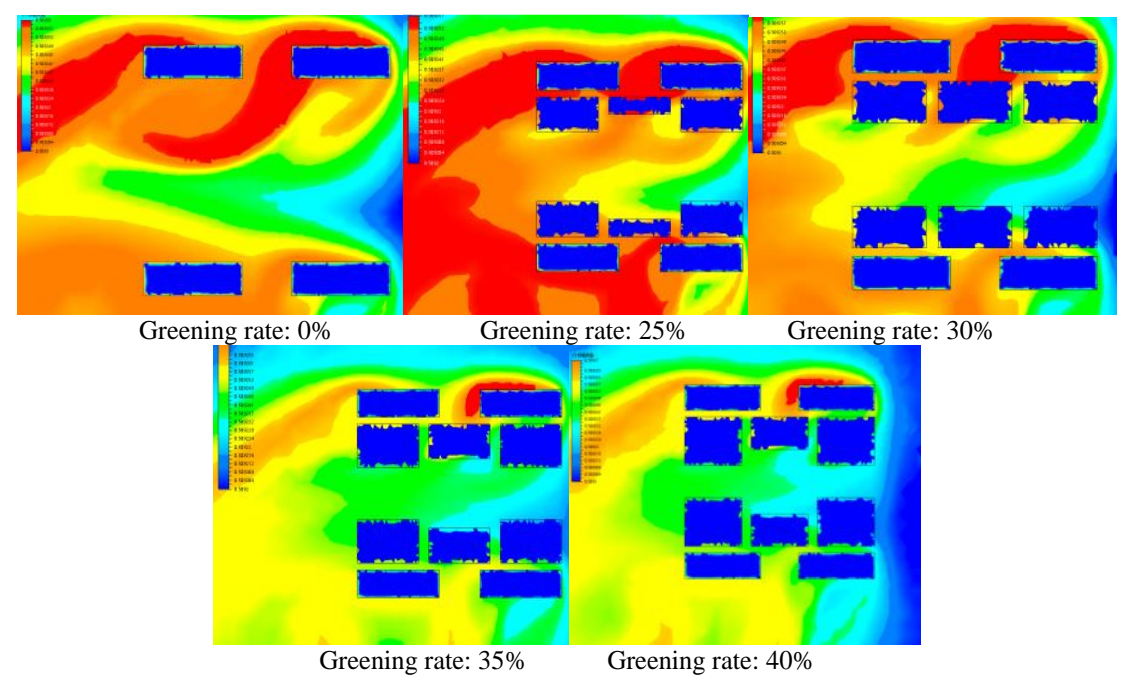

Figure 21. Distribution of fine particulate matters of clusters with different greening rates

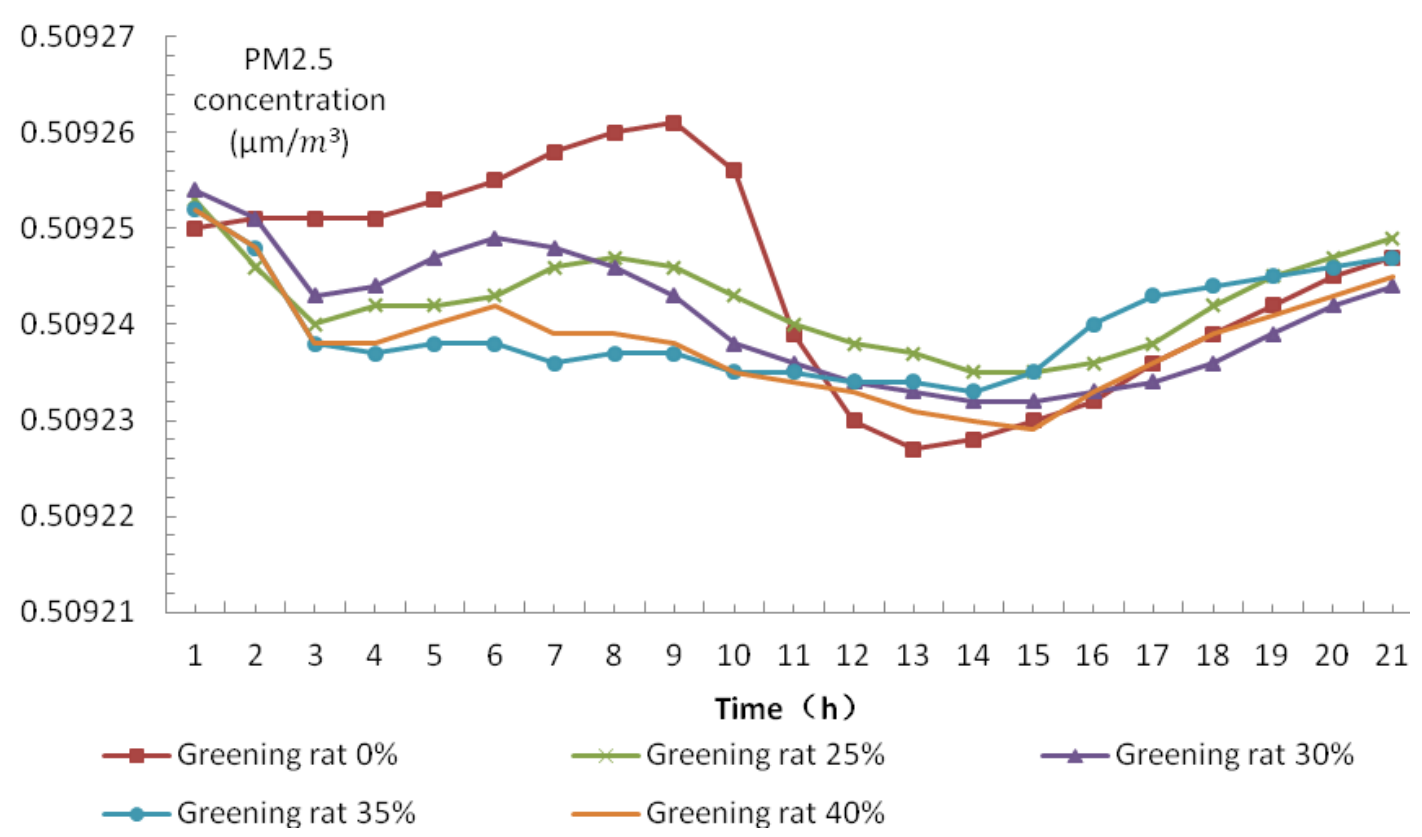

Figure 22. Distribution of fine particulate matters on west-side air outlet in the cluster space with different greening rates at an altitude of $1.5 \mathrm{~m}$

The comparison discovers that the concentration of particulate matters in the space of urban residential clusters is negatively related to the greening rate, which is especially 
significant in open space. However, a node appears. When a greening rate reaches a certain height, the concentration will decrease with the elevation of greenbelts, tending to be stable. This means that when the green land area reaches a certain height, excessively blocking and influencing field wind environment, wind speed will be largely reduced, dynamic factors for the spread of suspended particulate matters will wear off gradually, while the decrease of concentration of suspended particulate matters will also wear off gradually till reach the steady state.

\section{Discussion}

In the current residential group development process, in order to pursue the maximum unit area yield of commercial real estate, various types of residential areas are trying to approach or break through the volume ratio index and building density index defined by the regulatory plan to the maximum extent. Under the premise of determining the total building amount, the overall cluster layout cannot effectively combine local regional characteristics, climatic conditions and other factors, ignoring that the overall layout of residential areas will have a negative impact on the distribution of suspended particulate matter in the city.

The micro-climate environment has an important impact on the design of urban residential groups. Masatoshi M. Yoshino classifies the local climate dimensions in Japan, which can be concluded that the environmental factors of climate usually include temperature, solar radiation intensity, wind speed, humidity, etc. As shown in Figure 23, microclimate influences the surrounding environment and climate through the coupling of various climatic factors. Under the same solar radiation condition, influenced by the roughness of underlying surface, the greater the roughness of underlying surface, the more it can promote the flow and heat transfer of wind. By understanding the interaction principle between microclimate factors and urban underlying surface, we can find the characteristic factors of microclimate environment of residential groups (Chauhan et al., 2012).

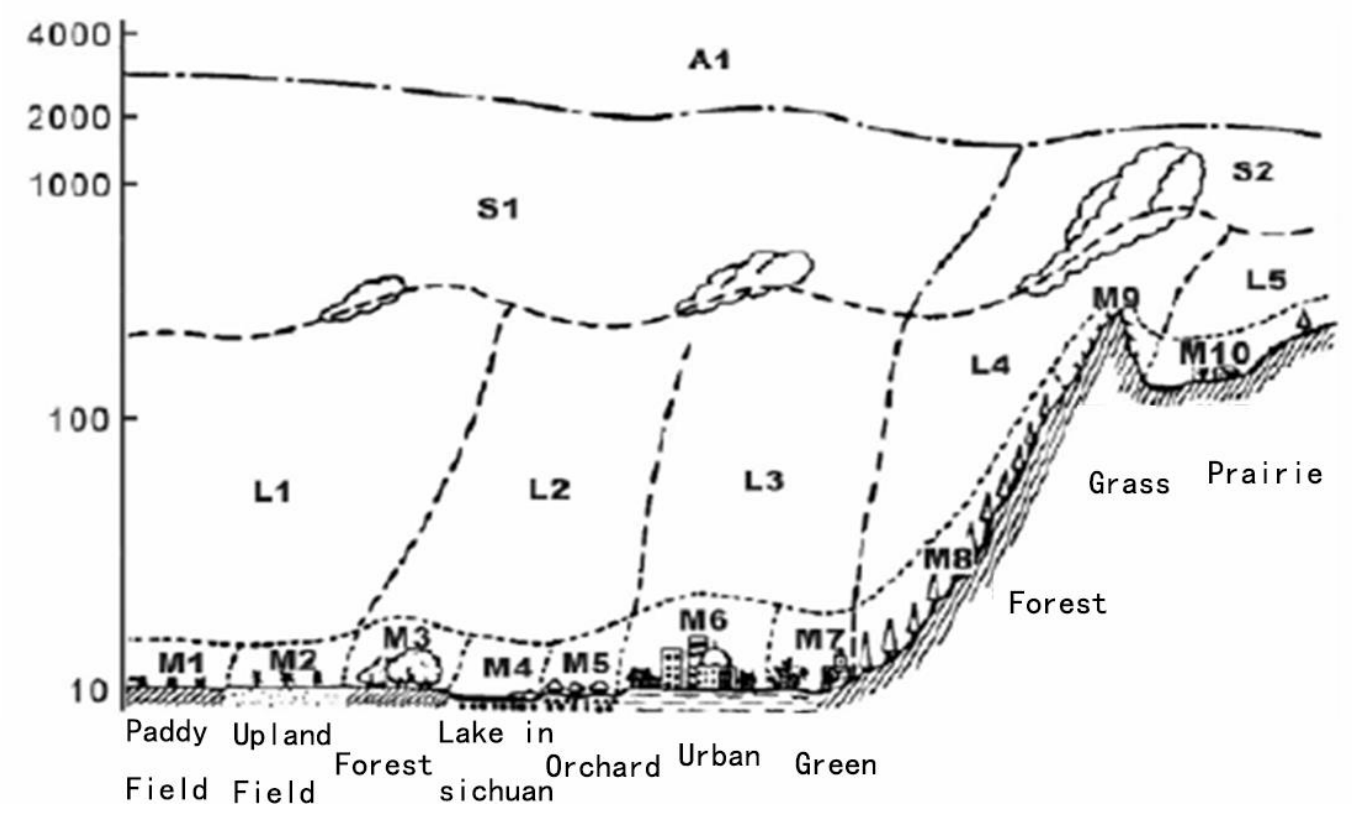

Figure 23. Climate range map (Chauhan et al., 2012) 
Based on the research and analysis of the influence factors of microclimate, it is concluded that the microclimate factors which have great influence on the spatial form of urban residential groups are as follows: 1 . Air circulation is reflected in the impact of the layout of buildings and buildings on microclimate. 2. Solar radiation and biological cooling are reflected in the change of microclimate caused by the absorption of heat radiation by greening vegetation communities. Vegetation can not only consume a lot of heat energy through transpiration in summer with intense sunshine radiation, but also increase the reflectivity of solar radiation by tree crowns. At the same time, plants can convert solar energy into biological energy, which reduces the fluctuation range of urban air layer. 3. Sun blocking effect refers to the use of buildings and trees, etc to shield the solar radiation, so as to reduce the absorption of solar radiation on the urban surface, so it will produce the climatic effect of reducing the environmental temperature in the shadows that appear in the shield (Sun et al., 2013); 4. Surface reflectance and temperature are reflected in the use of building surface materials and the impact of landscape paving materials on the temperature of microclimate 5. Evaporation and humidity; First of all, humidity is an important factor affecting natural ecological climate differences such as clouds, rain, fog and so on and is also an important factor affecting human comfort. In urban residential groups, this can increase and decrease air humidity through evaporation of underlying surfaces with different water seepage rates to achieve "passive" cooling (Sun et al., 2013). Many factors around residential group space influence the generation of microclimate, as shown in Table 4.

Table 4. Signature characteristics of microclimate influencing factors and residential group composition factors

\begin{tabular}{c|c|c}
\hline $\begin{array}{c}\text { Correlation } \\
\text { factors }\end{array}$ & Signature characteristics & Effect on microclimate \\
\hline Space shape & Plane form and elevation form & Air circulation \\
\hline Green space & Greening Area, tree species & Wind speed reduction \\
\hline Shaded condition & Buildings, trees & Direct radiation heating \\
\hline $\begin{array}{c}\text { Topographic } \\
\text { roughness }\end{array}$ & $\begin{array}{c}\text { Building distribution, average height, orientation and } \\
\text { volume; extent of spatial openness }\end{array}$ & $\begin{array}{c}\text { Scattering radiation } \\
\text { warming }\end{array}$ \\
\hline Surface reflectance & Building and ground material & Radiation warming \\
\hline $\begin{array}{c}\text { Evaporation of } \\
\text { underlying surface }\end{array}$ & Green space and water body & Decalescence \\
\hline
\end{tabular}

The research in this paper was taken as a new method and new thought to conduct quantitative analysis and predict the microclimate with the greening rate of urban residential clusters, based on the spread of suspended particulate matters, further advancing the ecologicalization and scientification of the landscape architecture discipline. The findings of this paper have provided application value for the construction of similar areas. The following perceptions are summarized:

(1) Indication factors of this paper were set by combining the specific regional characteristics of Xi' an city. Therefore, in the future researches of other cities, such as Guanzhong, or even cities of lower temperature on average, the corresponding index parameters can be adjusted combining regional and cultural characteristics.

(2) Since spatial arrangement of urban greenbelts can be viewed from the plane and vertical plane perspectives, near ground microclimate is related to the greening 
structure, quantity of greenbelts, spatial form of greenbelts and landscape pattern, etc., there are still factors in need of exploration in a further way.

(3) To certain extent, meteorological simulation software has relatively larger mesh calculation scale. Therefore, when studying micro-climatic factors, CFD is more suitable for the purpose of numerical simulation.

\section{Conclusion}

The increase of urban greenbelts and the improvement of urban underlying surfaces can realize the temperature reduction. On one hand, a great amount of greening volume can reduce the concentration of suspended particulate matters by alleviating heat island effect. On the other hand, greenbelts can greatly purify and retain particulate matters, and the wider range of greenbelts, the more effective.

In the space of residential clusters, different greening rates have been obtained through CFD simulation: concentration of particulate matters in the space of residential clusters is negatively related to the greening rate overall, and is especially significant in open space. However, a node appears. When the greening rate exceeds $40 \%$, the degree of the concentration reduction with the elevation of greenbelts decreases, with the tendency to be stable. By making comprehensive analysis on the preferences of sectional turbulence characteristics and preferences of pollutant concentration of the cluster examples, this study has come to the conclusion that the optimal plan of greening rate is the cluster plan with the greening rate of $35 \%$ and $40 \%$. The plan with the greening rate of $30 \%$ is optional, the plans with the greening rate of $0 \%$ and $25 \%$ are inappropriate, as shown in Figure 24.

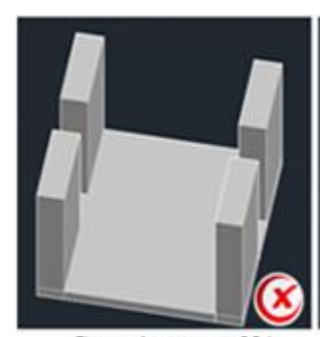

Greening rate: $0 \%$

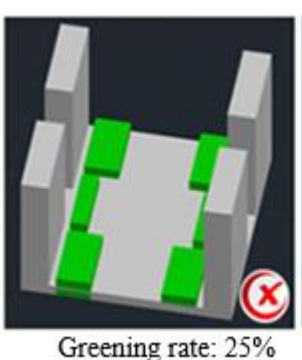

Greening rate: $25 \%$

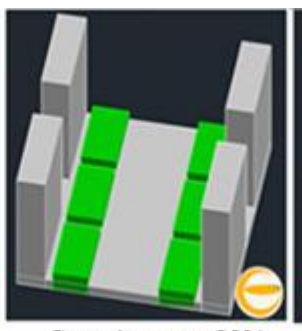

Greening rate: $30 \%$

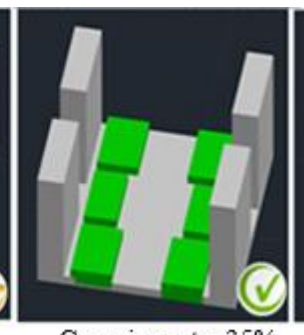

Greening rate: $35 \%$

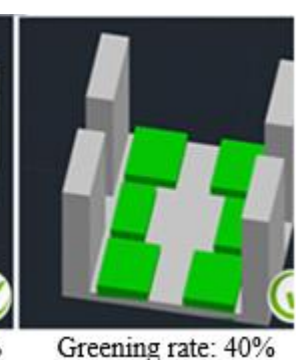

Greening rate: $40 \%$

Figure 24. Judgement on the sections of particulate matter concentration with different greening rates

Acknowledgements. This paper is supported by The Project Supported by Natural Science Basic Research Plan in Shaanxi Province of China (Program No. 2019JQ-567) \& Natural Science Foundation of China (NSFC): Influence Mechanism and Control of Urban Space Constitution on the Distribution of Suspended Particulate Matters (Program No. 51678058) \& The Project Supported by Social Science Basic Research Plan in Shaanxi Province of China (Program No. 2018S18).

\section{REFERENCES}

[1] Chai, Y., Zhu, N., Han, H. (2002): Dust retention effect of urban greening species - take Harbin for example. - Chinese Journal of Applied Ecology 9: 1121-1126. 
[2] Chauhan O S, Kader U S A, Vaidya P, et al. Dispersal and sink pathways of suspended particulate matter from the orographically enhanced SWM regime of the SE Arabian Sea[J]. International Journal of Remote Sensing, 2012, 33(14):4393-4407.

[3] Che, S., Song, Y. (2002): Analysis of the landscape pattern of Shanghai Municipal Park green space. - Journal of Shanghai Jiaotong University (Agricultural Sciences) 4: 322.

[4] Cheng, X., Hu, N., Cui, G., et al. (2004): Numerical study of pollutant dispersion in urban area. - Urban Environment and Urban Ecology 17(4): 1-4.

[5] Dai, T. (2006): Urban Environmental Ecology. - China Building Materials Press, Beijing.

[6] Ding T P, Gao J F, Tian S H, et al. Silicon isotopic composition of dissolved silicon and suspended particulate matter in the Yellow River, China, with implications for the global silicon cycle[J]. Geochimica Et Cosmochimica Acta, 2011, 75(21):6672-6689.

[7] Fanger, P. O., Toftum, J. (2002): Extension of the PMV model to non-air-conditioned buildings in warm climates. - Energy and Buildings 34(6): 533-536.

[8] Feng, X., Chu, Y. (2017): Study of the local microclimate effect of urban greenbelts based on aerodynamics simulation. - Chinese Landscape Architecture 2: 29-34.

[9] Feng, X., Gao, K., Zhong, S. (2014): Study of the influence of green layout of urban greenbelts on microclimate of some areas based on GRAPES numerical simulation. South Architecture 3: 10-16.

[10] Feng, X., Wang, S. (2004): Model study of urban architectural ecological layout. Proceedings of 2004 annual Meeting of Urban and Rural Planning: Urban Ecological Planning, pp. 525-529.

[11] Horemans B. Assessment of the water soluble ionic species of suspended particulate matter, collected at a coastal spot, De Haan, Belgium[J]. Journal of Neurophysiology, 2007, 76(3):1439-56.

[12] Hu, S. (2002): Three dimensional transient gas release of gas source diffusion of. Science and Technology of Labour Protection 3(20): 28-30.

[13] Jasinski, R. (2017): Problems of the starting and operating of hydraulic components and systems in low ambient temperature (Part V). Methods ensuring correct start-up of hydraulic components of ship's onboard devices in low ambient temperatures. - Polish Maritime Research 24(4): 47-56.

[14] Kmita, A., Fischer, C., Hodor, K., Holtzer, M., Roczniak, A. (2017): Thermal decomposition of foundry resins: a determination of organic products by thermogravimetry-gas chromatography-mass spectrometry (Tg-Gc-Ms). - Arabian Journal of Chemistry 11(3): 380-387.

[15] Li, D., Wang, L., Peng, W., Ge, S., Li, N., Furuta, Y. (2017): Chemical structure of hemicellulosic polymers isolated from bamboo bio-composite during mold pressing. Polymer Composites 38(9): 2009-2015.

[16] Liu, Y., Li, T., Guo, L., Zhang, R., Feng, X., Liu, K. (2017): The mediating role of sleep quality on the relationship between perceived stress and depression among the elderly in urban communities: a cross-sectional study. - Public Health 149: 21-27.

[17] Ma, X., Zhao, J., Guo, P. (2017): Influence of the plane form of courtyard-type residential clusters on the spread of PM2.5. - Journal of Architecture and Civil Engineering 34(4): 120-126.

[18] Meir, P., Grace, J., Miranda, A. C. (2000): Photographic method to measure the vertical distribution of leaf area density in forests. - Agricultural and Forest Meteorology 102(2): 105-111.

[19] Ministry of Housing and Urban-Rural Development of the people's Republic of China (MOHURD) (2002): Code for Planning and Design of Urban Residential Areas. GB50180-2002.

[20] Ministry of Housing and Urban-Rural Development of the people's Republic of China (MOHURD) (2010): Design Standard for Energy Efficiency of Residential Buildings in Severe Cold and Cold Zones. - JGJ 26-2010. 
[21] Nikolopoulou, M., Baker, N., Steemers, K. (2001): Thermal comfort in outdoor urban spaces: understanding the human parameter. - Solar Energy 70(3): 227-235.

[22] Pape P L, Morin G, Jouvin D, et al. Zinc Speciation in the Suspended Particulate Matter of an Urban River (Orge, France): Influence of Seasonality and Urbanization Gradient[J]. Environmental Science \& Technology, 2014, 48(20):11901-9.

[23] Peng, X., Jiang, J. (2002): Development of urban air pollutant diffusion simulation system. - High Altitude Meteorology 21(2): 139-144.

[24] Periáñez R. Modelling the transport of suspended particulate matter by the Rhone River plume (France). Implications for pollutant dispersion.[J]. Environmental Pollution, 2005, 133(2):351-364.

[25] Safaei-Ghomi, J., Enayat-Mehri, N., Eshteghal, F. (2018): 4-(4 -Diamino-Di-Phenyl)Sulfone Supported On Hollow Magnetic Mesoporous Fe3O4@Sio2 Nps: As a Reusable and Efficient Catalyst for the Synthesis of Ethyl 2-Amino-5, 10-Dihydro-5, 10-Dioxo-4Phenyl-4H Benzo Chromene-3-Carboxylates. - Journal of Saudi Chemical Society 22(4): 485-495.

[26] Salamanca, F., Martili, A., Tewari, M. et al. (2009): A study of the urban boundary layer using different urban parameterisation and high-resolution urban canopy parameters with WRF.- Journal of Applied Meteorology and Climatology 48: 484-501.

[27] Su, Z., Liu, Y., Peng, Q. (2002): Research of the dust retention effect of different greenbelt types in cities. - Arid Environmental Monitoring 3: 162-163.

[28] Sun J, Khelifa A, Zheng X, et al. A laboratory study on the kinetics of the formation of oil-suspended particulate matter aggregates using the NIST-1941b sediment.[J]. Marine Pollution Bulletin, 2010, 60(10):1701-1707.

[29] Sun J, Zhao D, Zhao C, et al. Investigation of the kinetics of oil - suspended particulate matter aggregation[J]. Marine Pollution Bulletin, 2013, 76(1-2):250-257.

[30] Tian, A. L., Li, G. X., Elsheikha, H. M., Gardner, D. S., Zhang, X. Y., Dong, W., Yang, X. P., Luo, Y. Y., Li, H. L., Cong, W., Zhu, X. Q. (2017): Seroepidemiology of Toxoplasma gondii infection in patients with liver disease in eastern China. Epidemiology and Infection 145(11): 2296-2302.

[31] Wahi, N., Bhatia, A. K., Bhadauria, S. (2018): Impact of Protozoan vahlkampfia sp on the growth of algae Chlorella vulgaris Glamtr. - Journal of Environmental Biology 39(1): 109-115.

[32] Zamora Figueroa, A. C., Ramos Oropeza, J. R., Arias, M., Hernandez Valencia, I. (2017): Response of the microbial community to the biotreatment of a soil contaminated with a medium crude. - Revista Internacional De Contaminacion Ambiental 33(4): 629-639.

[33] Zhang, W. (2015): Simulation study of the influence of green layout of residential areas on microclimate. - Master Thesis of Nanjing University.

[34] Zhao, J., Liu, J. (2001): Garden style summer thermal environment research. - Journal of Northwest Institute of Architectural Engineering (Natural Science Edition) 18(1): 8-11.

[35] Zhou, J. (2001): Urban green volume calculation mode and information system. - Acta Geographica Sinica 1: 14-23.

[36] Zhu, N., Li, M., Chai, Y. (2002): Analysis of the ecological functions of the green space system in Harbin greenbelts. - Chinese Journal of Applied Ecology 9: 1117-1120. 